\title{
الاستدامة كنهج بيئي في العمارة الاخلية السعودية المعاصرة \\ Environmental sustainability approach in contem porary \\ Saudi internal architecture
}

الباحثة د/ دلال صالح الثمراني

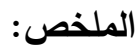

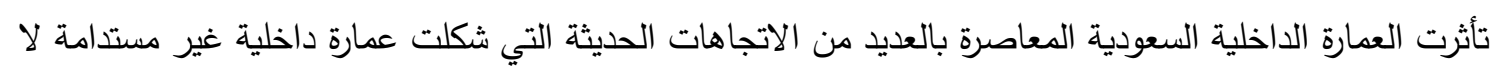

توافق اهدافها التصميمية مع الواقع الطبيعي القائم، حيث أدى التطور التكنولوجي التقني المعاصر التى تجاتهاتهل البيائة الطبيعية

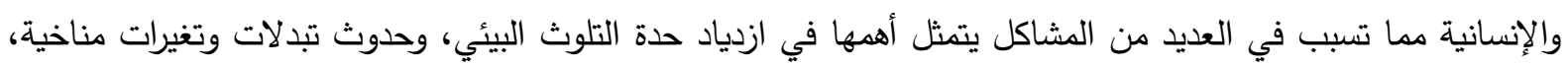

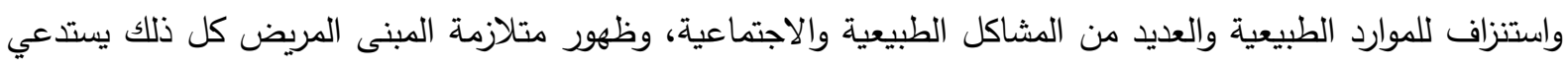
ضرورة تحديد علاقة تبادلية بين مبادئ الاستدامة والجوانب التصميمية عن طريق ايجاد حلول بيئية موفرة للطاقة وللموارد تسهم في رفع أداء المبنى وتحقق التكامل في التصميم. ويقوم هذا البحث بدراسة وتحليل فكر ومحددات التصميم المستدام

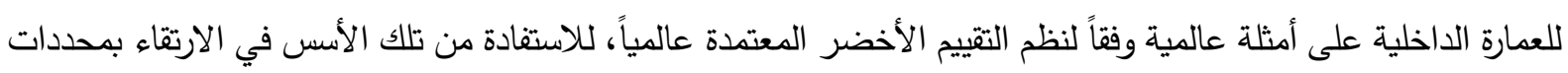
تصميم العمارة الداخلية في المملكة العربية السعودية، وتلافي سلبيات التجارب السابقة سواء محلية أو عالمية، وتطويع فكر الإني التصميم المستدام من خلال الإمكانات المتاحة للوصول لعمارة داخلية تحقق الأهداف البيئية في ظل الموارد المحدودة. الكلمات المفتاحية:

Sustainability الاستدامة:

Sustainable interior Design التصميم الداخلي المستدام الاسنغام Ecological Interior architecture العمارة الداخلية البيئة Environmental pollution التلوث البيئي

Renewable energy الطاقة المتجدة التطور التكنولوجي Technological development المقدمة:

شهر القرن العشرين تحولاً شاملاً في مجالات العمارة الداخلية السعودية تحت لواء الحداثة، معارضاً جميع التقاليد المعمارية ومُقبلاً على استغلال التقنيات والتكنولوجيا بدون وعي فقعدت العمارة الداخلية السعودية التقليدية طابعها الجمالي والذي كان يطبق وبشكل عفوي وتلقائي مبادئ الاستدامة. حيث يعد النشاط المعماري من أكثر الأنشطة الإنسانية استنفاذاً للموارد البيئية الغير متجددة والمتسبب في حدوث أزمات بيئية تتمثل في التلوث البيئي ومردوده السلبي على جماليات البيئة.

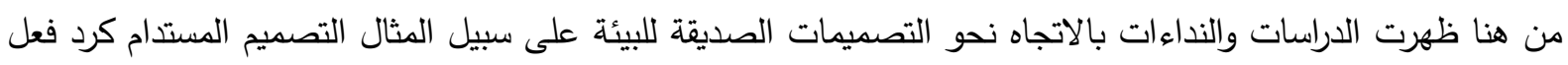
للأزمات البيئية، والنمو السريع للنشاط الاقتصادي والسكاني، ونضوب الموارد الطبيعية، والأضرار التي لحقت بالنظم الإيكولوجية. فأصبحت ثقافة الحفاظ على البيئة ومعرفة دورة المنتج وتدوير المخلفات والحفاظ على الطاقة هي من أبرز القضايا في مجالات التصميم والبيئة. ففي هذا البحث يتم توجيه الاهتمام على هذا النهج البيئي ودوره في تلبية احتياجات

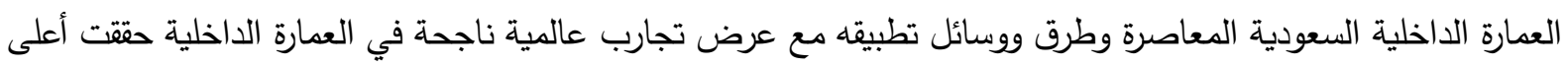
معايير التقييم المستدام يمكن الاحتذاء بها. 
1. تليط الضوء على هذا المنهج البيئي في التصميم الداخلي والذي يقوم أساساً على الاستفادة من معطيات التكنولوجيا بما لا يؤثر سلباً على البيئية بهدف الحد من التلوث وتحقيق الكفاءة البيئية والاعتدال في استهلاك الموارد الطبيعية وتأمين مستثبل الأجيال القادمة. 2. تطوير العمارة الداخلية السعودية بصورة أكثر استدامة بتطبيق مفاهيم التصميم المستدام للوصول لبيئة صحية صالحة للإنسان بأقل مخاطر في المستقبل.

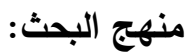

يعتمد هذا البحث لحل مشكلته ولتحقيق أهدافه على المنهج الوصفي التحليلي من خلال وصف مفهوم الاستدامة

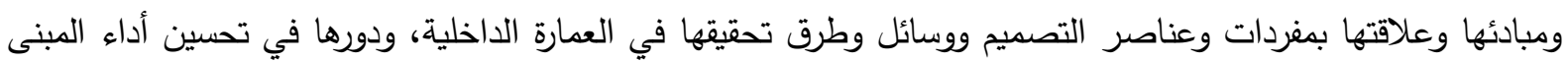
وعلاقته بالبيئة. كما يستتد البحث على المنهج التحليلي في عرض نماذج عالمية مستدامة حازت على شهادات معتمدة من

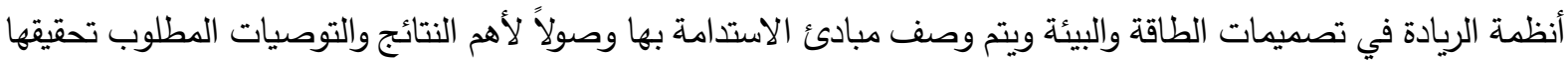
والتي تسهم بدورها في توجيه امكانياتنا لتصميم عمارة داخلية سعودية مستدامة معاصرة. 1. مفهوم الاستدامة في العمارة الاخلية، وأهدافها: تُعرف الاستدامة من قبل المجلس الوطني للتصميم الداخلي (NCIDQ) بأنها طريقة لممارسة أو استخدام المواد والموارد التي هي قادرة على الاستمرار مع أدنى تأثير على البيئة (NCIDQ). ويُعرف التصميم المستدام بأنه فلسفة تصميم تسعى إلى زيادة جودة البيئة المبنية، مع التقليل الى أدنى حد من التأثير السلبي على البيئة الطبيعية أو القضاء على لئيه

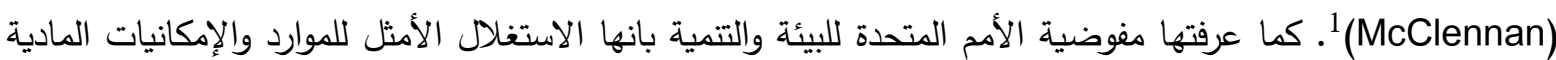
والطبيعية بشكل متوازن ومناسب للبيئة دون الاهمال لمتطلبات واحتياجات الأجيال القادمة.

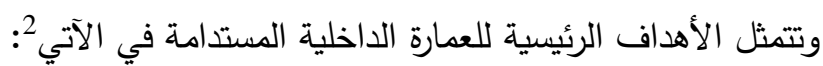
- - فاعلية المواد المستخدمة. - - - - مفأه أداء الطاقة.

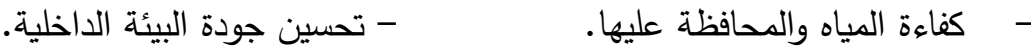

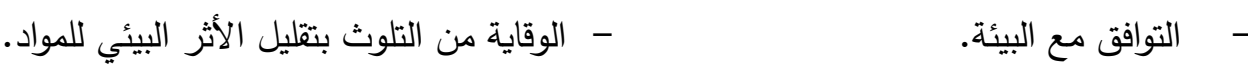
- - موظيف مبادئ التقييم المتكامل والتشغيل والإدارة (تحقيق التكامل).

2. باية ظهور هذا المنهج في العمارة الداخلية: ظهرت العمارة البيئية المستدامة في الحضارات القديمة في صورة محاولة الإنسان للتأقلم والتعايش مع بيئته وتباينت

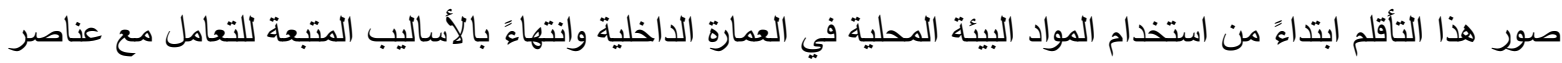

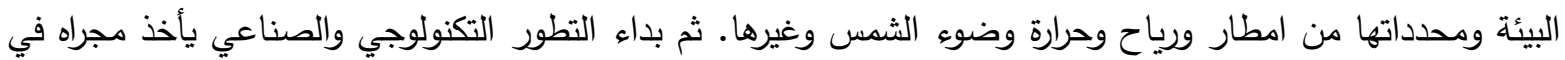

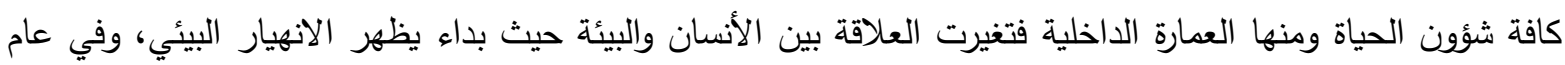

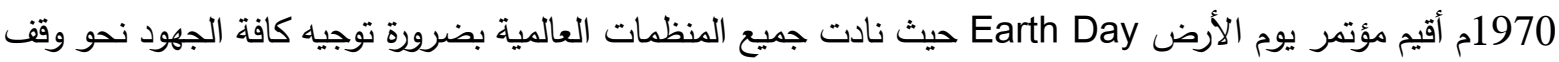

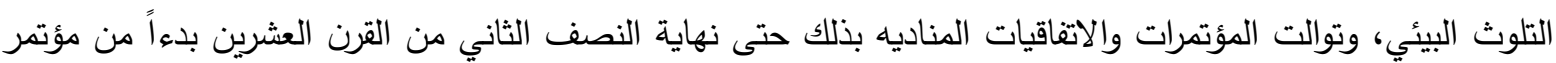

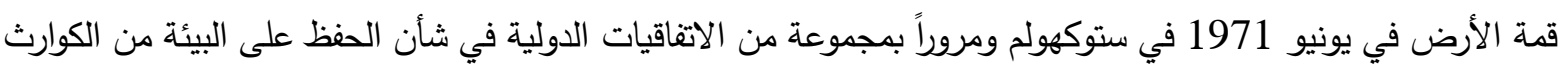

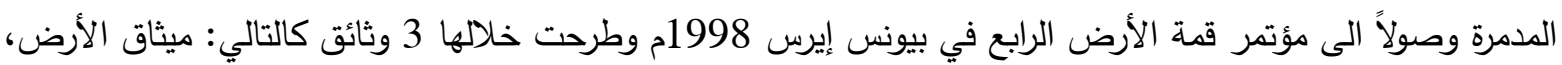

1 Clennan, Jason F. (2004) The Philosophy of Sustainable Design. Bainbridge Island: Ecotone Publishing Company.

2 Florez, Laura and Daniel Castro-Lacouture (2012) "Optimization model for sustainable materials selection using objective and subjective factors" Materials and Design, 46:310-321. 
واجندة القرن الـ21 ، واتفاقية تغير المناخ، ومن هنا ظهر مبدأ الاستدامة Sustainability كواحدة من أهم المداخل لتطبيق أساليب الحفاظ على نوعية البيئة مع تحقيق التتمية التي ينشدها الأنسان في مجتمعه وقابلية الاستمرار والتواصل في والهي الاتجاهين (الحفظ والتتمية).

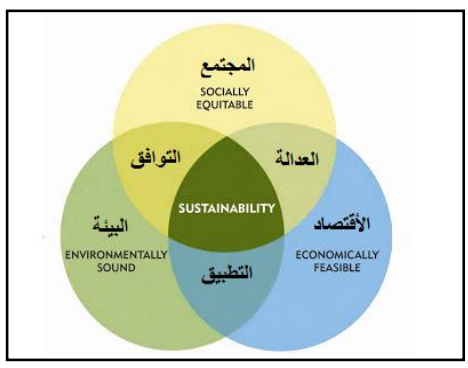

شكل رقم (1) محاور الأستدامة للأستدامة ثلاثة محاور تعتبر الدعائم المائم الرئيسية لها باختلال أحدهم تتأثر الأهداف.

\section{3. مبادئ الاستدامة في العمارة الداخلية:}

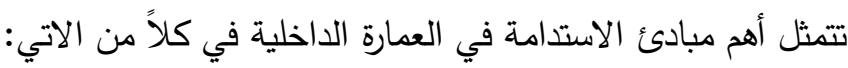
أ- التعلم من النظم الطبيعية (مبدأ المحاكاة الحيوية). ب- - احترام الطاقة والموارد الطبيعية (مبدأ الحفظ). ج- احترام الناس (مبدأ حيوية الإنسان). د- احترام المكان (مبدأ النظام الإيكولوجي). هـ - - دترام حق الأجيال القادمة.

4. الأبعاد المحورية للاستدامة في العمارة الداخلية: تتمثل أهداف التصميم المستدام في العمارة الداخلية في تحقيق الجودة المتكاملة كالآتي:

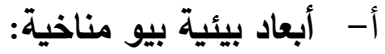

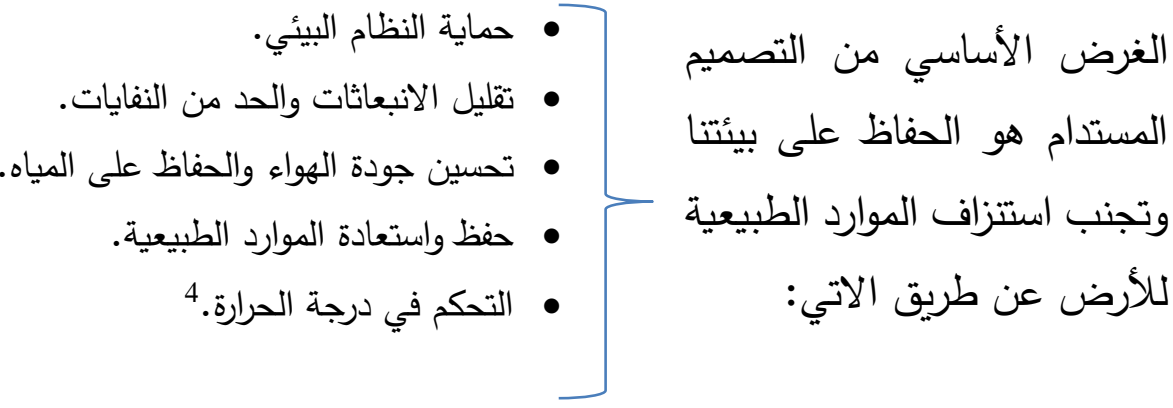

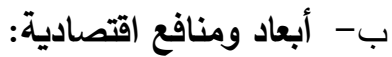

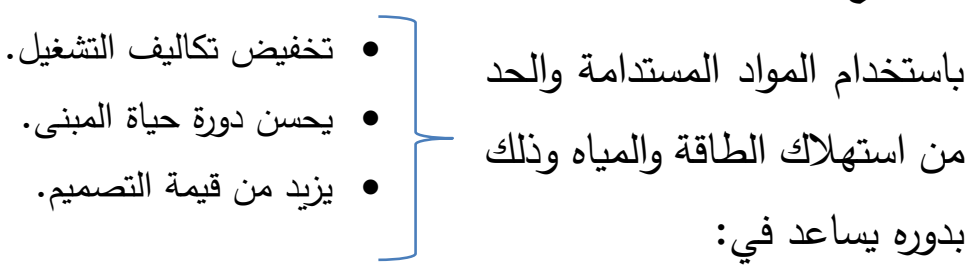

ج- - أبعاد وأهداف اجتماعية:

تحقيق راحة للمستخدمين وتحسين الصحة.

• التقليل من الضغط على البنية التحتية المحلية.

تحسين إنتاجية المستخدمين.

خلق بيئة مرحة جمالياً.
تتحقق المنافع من خلال تحسين

جودة البيئة الداخلية كالاتي:

3 Clennan,Jason F (2004)The Philosophy of Sustainable Design. Bainbridge Island: Ecotone Publishing Company.

4 Kang, M., \& Guerin, D.A. (2009). The state of environmentally sustainable interior design practice. American Journal of Environmental Sciences.

5 Giovani, Baruch (1998) Climate Considerations in Buildings \& Urban Design, John Wiley \& Sons, Inc, USA. 


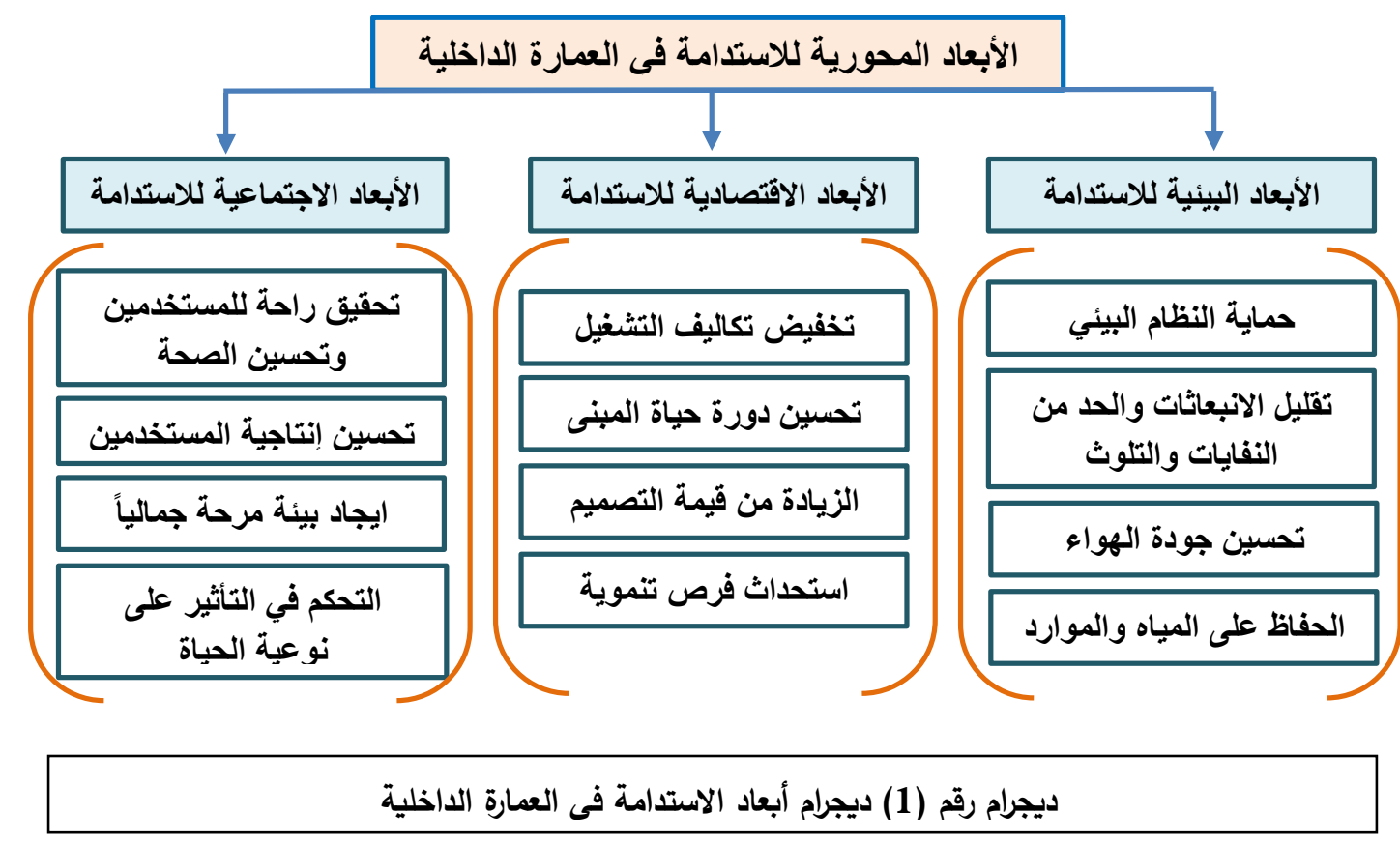

5. الظروف التي أدت إلى ولادة هذا التوجه في العمارة الداخلية: أدى استخدام الأنسان الغير مسئول للموارد والبيئة وخصوصاً بعد الثورة الصناعية وبداية عصر المكنة الى ظهوده فلى مشاكل

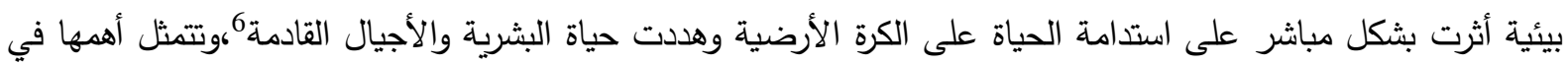

$$
\begin{aligned}
& \text { الآتي: } \\
& \text { أ- - تأكل وتهتك المحيط الحيوي للأرض. }
\end{aligned}
$$

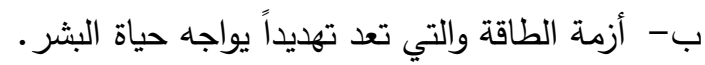

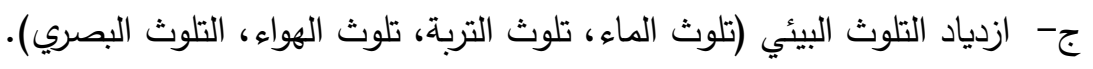

$$
\begin{aligned}
& \text { د- الزيادة السكانية. } \\
& \text { هـ - حصول تبدلات وتغييرات مناخية (مشكلة الاحتباس الحراري). } \\
& \text { و - استنزاف الموارد الطبيعية زيادة في الطلب عليها. } \\
& \text { ز - التوسع الصناعي والاكتثافات التكنلوجية الحديثة. } \\
& \text { ح- المشاكل الصحية والاجتماعية. }
\end{aligned}
$$

ط- ظهور متلازمة المبنى المريض الذي يسبب للقاطنين الصداع والمشاكل التتفسية والسبب قلة التهوية الطبيعية7.

\section{6. طرق ووسائل تحقيق الاستدامة في العمارة الداخلية السعودية المعاصرة:}

هناك عدة عوامل طرق ووسائل لابد من مراعاتها لتحقيق الاستدامة في تصميم العمارة الداخلية لأي بناء حيث تجعل مواصفاته متوافقة مع البيئة وأداؤها يتسم بالكفاءة سواء في استهلاك الطاقة أو في تأثيره البيئي وتتمثل في كلاً من

$$
\text { الآتي 8: }
$$

6 Wael Rashdan (2016) The impact of innovative smart design solutions on achieving sustainable interior design, International th11 Conference on Urban Regeneration and Sustainability.

7 Sustainable Design: U.S. General Services Administration, 3 Nov. 2012. Web. 2 Dec. 2012. http://www.gsa.gov/portal/content/10446.

8. Mate, K.J. (2006) Champions, Conformists and Challengers: Attitudes of Interior Designers as Expressions of Sustainability through Material Selection. Paper 0066. presented at Design Research Society International Conference. Wonderground. 1-4 November, Lisbon. 
أ-كفاءة استخدام الطاقة: تُعبر كفاءة استخدام الطاقة عن إمكانيات المبنى في تخفيض معدلات استهلاكه للطاقة الخاصة بعمليات تشغيله، و ذلك عن طر بو :

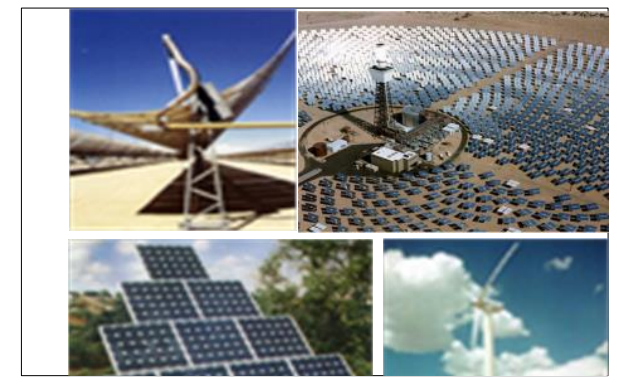

شكل (2) المتعد

مصادر الطاقة المتحددة. استخدام مصادر الطاقة المتجددة الأقل تأثيراً على البيئة:

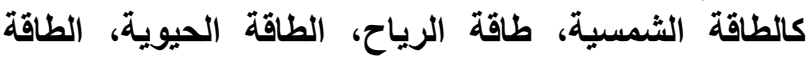

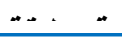

ترشيد استهلاك الطاقة واختيار أجهزه ومعدات موفرة للطاقة.

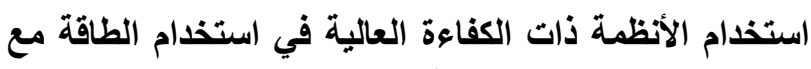
عمل، محاكاة لاستعلاك الطاقة ف، المنـ, قلى انثائه.

ب- - التصميم تبعًا للعوامل المناخية: ملائمة المبنى للظروف المناخية المحيطة به بهدف تخفيض استهلاك الطاقة وتوفير بيئة صحية ومويحة من خلال تحقيق القيم المثلى لعوامل الراحة المناخية في الأجواء (البردة، المعتدلة، الحار الجاف، الحار الإطب، شديد الروة) وتتمثل أهم المحاور في الآتي:

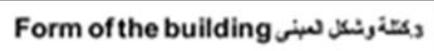

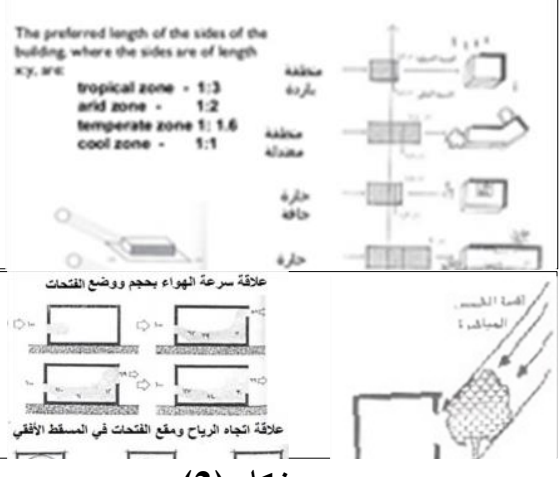

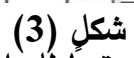

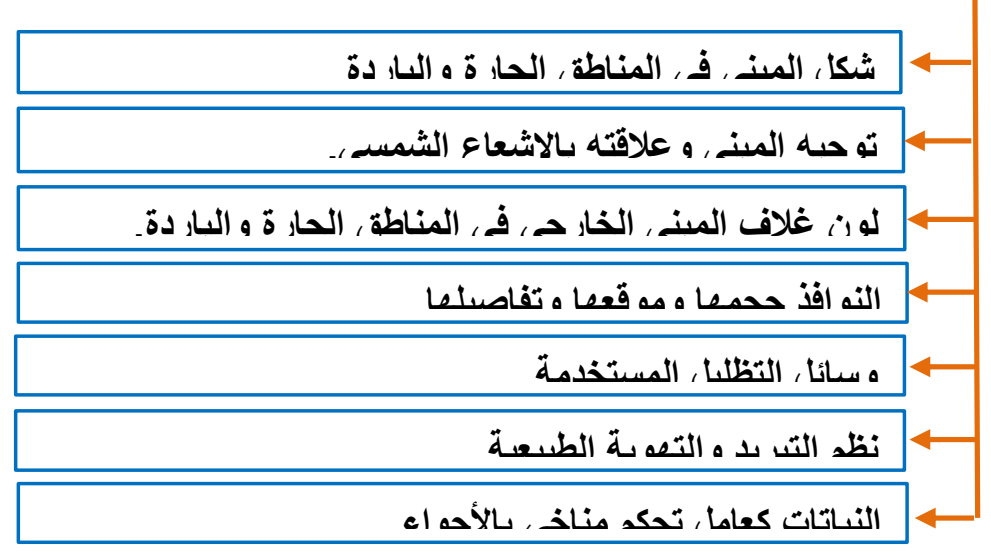

تصمد المنح، تسعلٍ للعُ (مل المناخة.

ج- التقليل والترشيد في المورد والمحافظة عليها وتلوريِ ها: يتطوق التصميم المستدام إلى دوة حياة تتلخص في منتجات تم تصنيعها ثم تداولهاواستهلاكها وفي النهاية التخلص منها كنفايات تحت

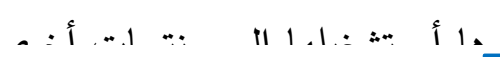

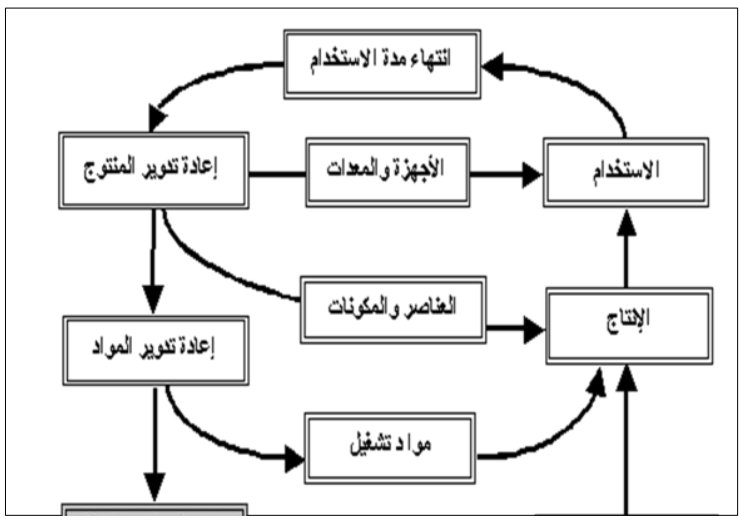

شكل (4) (1)

أنواع ودورات إعادة التووير.
الخفض: في استهلاك الموارد الطبيعية سواء أهواء

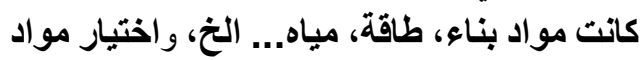

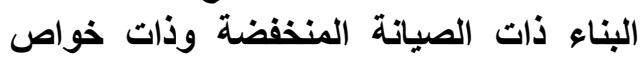
تجنب المبنى فقد الكثير من الطاقة خلال عمليات التهات الت لد ه التدفئة، كذلك استخداد مه اد لا لا بنطلب عملات

إعادة الاستخدام: المواد المعاد استخدامها لا

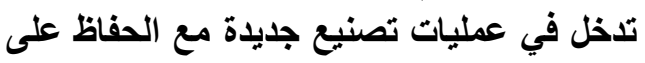
إعادة التصنيع: تعني إدخال المخلفات بعمليات

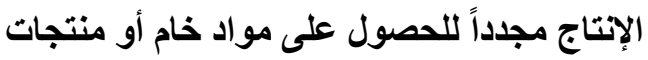
يمكن أن تشارك في بناء أو تثغيل المبنى. 
د- جودة البيئة الداخلية: قرة التصميم في تحقيقراحة الإنسان على احتمال النظام البيئي العام وتوكز هذه الاستر اتيجية على تغيز التعايش بين المباني والبيئة الأكبر وبين المبنى وشاغليه.
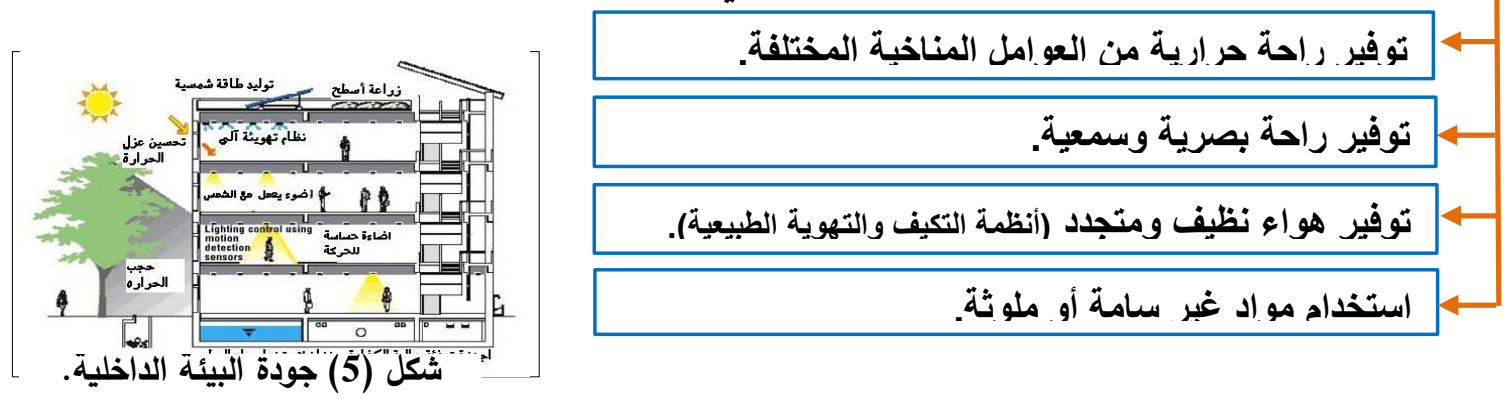

هـ - كفاءة استخدام المياه: لتحسين كفأه المياه داخل المباني يجب اعتماد طريقة منهجية حيث تقدم أنظمة الاستدامة استّاتيجيات تساعد على استهلاك المياه بشكل أمثل وتتمثل بالآتي:

الأعداد و التخطيط المبئي بأجراء مسح للمرافق ومراقبة الاستعمال الجيا وتحديد أهاف الأداء.

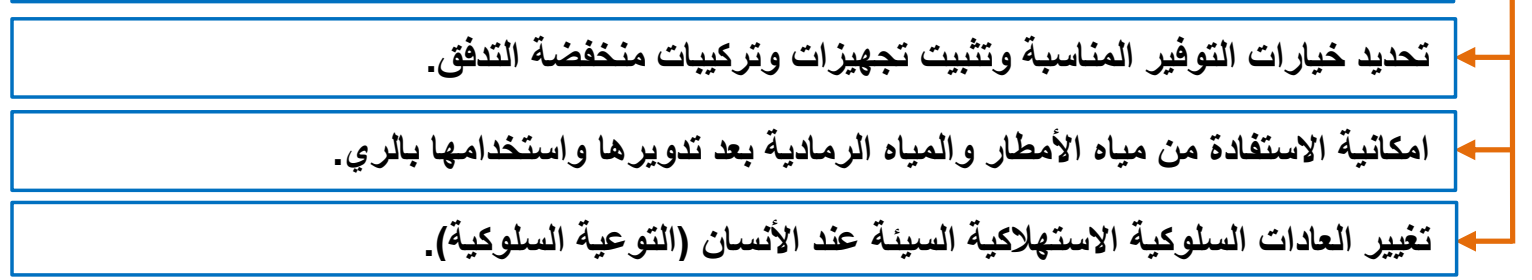
و - التصميم الداخلي مع الوضع في الاعتبار أمكانيات الموقعوالحفاظ على البيئة الطبيعية ويتحقق ذلك عن طويق الاتي: احترام الموقع واستفلال إمكانياته ومميزاته الطبيعية أثناء التصميم للحفاظ على الطاقة والمواد.

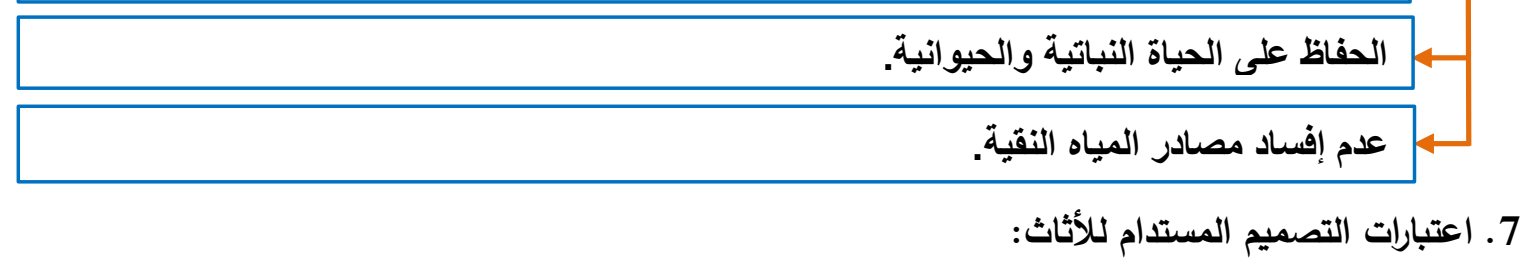
أ- أن ينثد التصميم المتانة وقوة التحمل من الناحية التقنية والجمالية. ب- امتلاك درجة عالية من الاتساق مع المنتجات الأخرى.

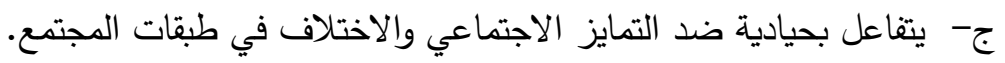

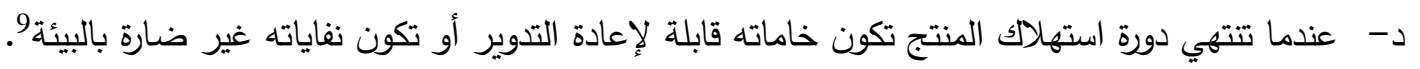

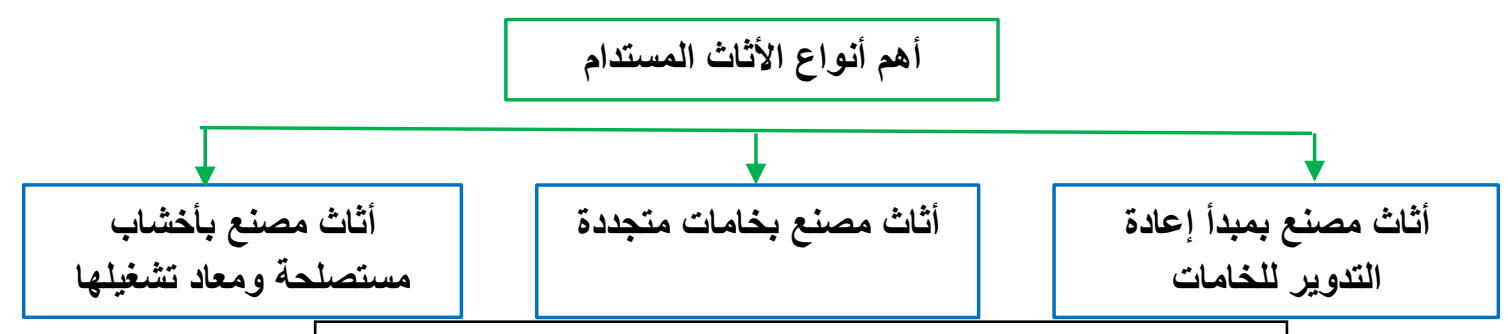

ديجرام رقم (2) أهم أنواع الأثاث المستدام في العمارة الداخلية

9 Nur Ayalp:( 2013) Multidimensional Approach to Sustainable Interior Design Practice, INTERNATIONAL JOURNAL of ENERGY and ENVIRONMENT, Issue 4, Volume 7. 
8. الاستدامة عبر تكامل مبادئ العمارة الداخلية التقليدية ونظم ووسائل التكنولوجيا الحديثة:

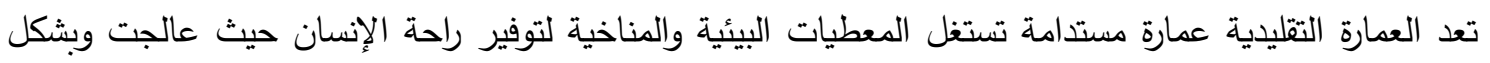

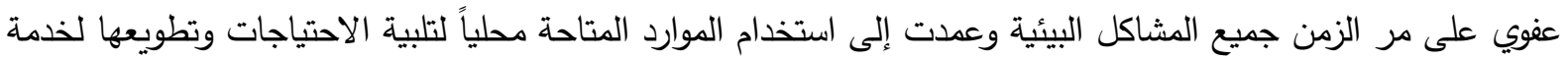
المبنى. أن التصميم المستدام للعمارة الداخلية السعودية المعاصرة اليوم يتحقق عبر تكامل مبادئ العمارة التقليدية مع نظم ووسائل التكنولوجيا الحديثة أذ أن هذا يحقق الحفاظ على مصادر البناء والطاقة الطبيعية، كما يحقق زيادة متانة التصميم وتوفير الراحة للمستخدمين مع توفير الطاقة وكلفة التثغيل والتقليل من التلوث والمخلفات، وتتمثل المعالجات البيئية الذكية

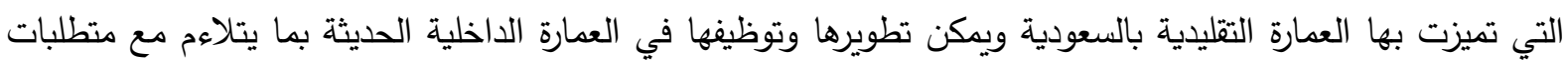

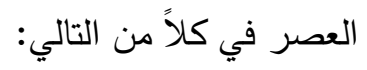

أ- الاستفادة من المعطيات البيئية والمناخية لتوفير راحة الإنسان والاستخدام الأمثل للتكنولوجيا.

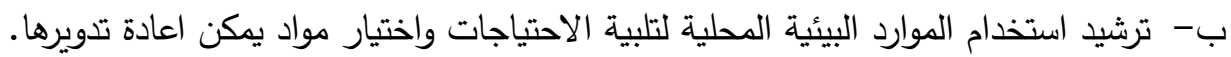
ج- تخفيض كلفة الطاقة بالمباني واستعمال الطاقات الطبيعية بدلا من أنظمة القوى الميكانيكية.

د- حسن توزيع الفراغات الداخلية وتحقيق نجاحاً في تدرج درجة حرارة الفضاءات الداخلية. هـ - أدخال النباتات في واجهات المباني والفراغات بغرض التضليل والاندماج مع الطبيعة.

9. أنظمة الريادة في تصميمات الطاقة والبيئة المعتمدة لتقييم مدى استدامة المبنى:

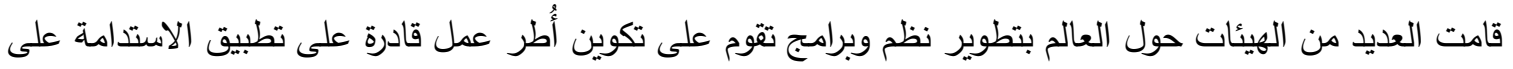

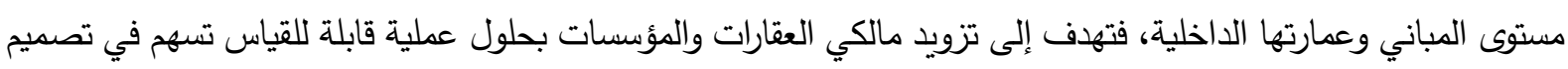

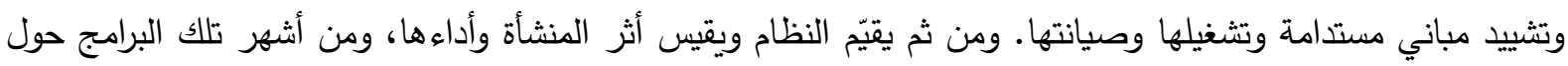

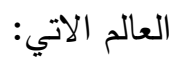

أ- نظام الريادة بتصميمات الطاقة والبيئة LEED: هو نظام لمجلس المباني الأمريكي USGBC هو اختصارا لـ Leadership in Energy and Environmental Design المائية، الانبعاثات، وتحسين البيئة الداخلية، ويصنف المباني الى أحد مستويات LEED البلاتيني أو الذهبي أو تواخئ

شكل رقم (6) المستويات الأربع لمعيار التقييم LEED ـ

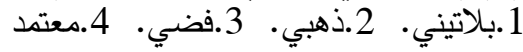

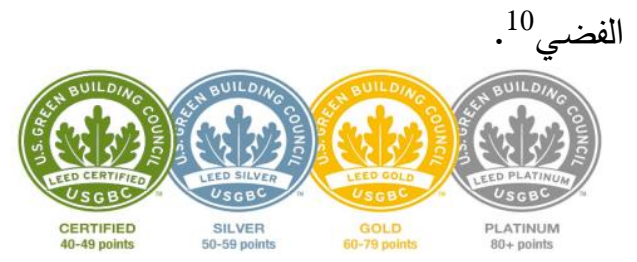

ب- بنام الريادة في التصميمات البيئة للمباني BREEAM: اختصار لـ Building Research Establishment Environmental Assessment Methodology للمجلس البريطاني للبناء المستدام والأخضر UKGBC والمعتمد منذ عام 1990م، يهدف الى تقييم الكفاءة البيئية للمباني القائعة والمباني الحديثة، تتمثل عناصر التثييم في: الإدارة، وصحة الإنسان، كفاءة الطاقة، كفاءة المياه، الموارد والمخلفات، التصميم الأيكولوجي، ونسبة التلوث، الابتكار 11.

ج- نظام تقييم المباني الخضراء بكندا Green Globes.

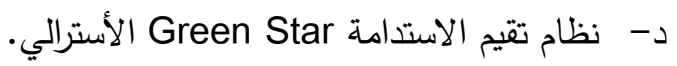

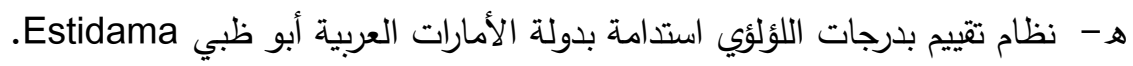

10 https://new.usgbc.org/leed - U.S. Green Building Council USGBC.

11 https://www.breeam.com - British Council for Sustainable Construction and Green UKGBC. 
10. أمثلة عالمية يتحقق بها أعلى قيم الاستدامة في العمارة الاخلية ويمكن الاحتذاء بها: يتم من خلال هذه النقطة البحثية القاء الضوء على جوانب الاستدامة ببعض المشاريع العالمية الناجحة وعرض الماءله وتحليل محددات الاستدامة المتبعة بها ذات العلاقة بكفاءة البيئة الداخلية للتصميم بالبيئة الخارجية، والحاصلة على معايير تقييم مرتفعة من أنظمة التقييم العالمية، حيث تثكل بحد ذاتها نماذجاً ملهمة لتصميم عمارة داخلية سعودية مماثلة مستدامة.

المثال الأول: المركز الفيدرالي الجنوبي 1202 بولاية واشنطن الأمريكية:12 الموقع: مدينة سياتل بولاية واشنطن في الثمال الغربي من الولايات المتحدة الأمريكية. المساحة الإجمالية: 20600 قدم مربع. - وتكلفة المشروع: 72 مليون دولار أمريكي. تصميم: شركة ZGF Architects LLP - مقاول البناء: Sellen Construction. الثركة المنفذة : نُفذ المشروع بتظافر جهود عدة مؤسسات حكومية وخاصة منها مؤسسة أعادة الاستثمار والانتعاش الأمريكي

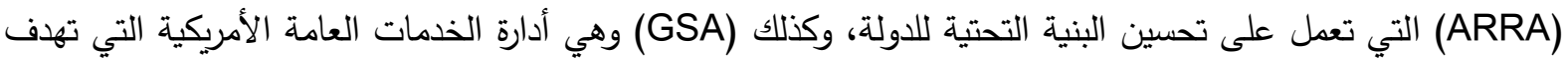
لتصديم مرافق ذات أداء وفاعلية عالية في الدوائر الحكومية الأمريكية مع أعادة استخدام وتوفير الطاقة. مدة تنفيذ المشروع: سنتان ونصف من مرحلة التصميم الى مرحلة التسليم، وسنة التتفيذ: 2012م. نوع المبنى: حكومي- مقر للمهندسين التابعين للجيش الأمريكي (USACE) للمنطقة الثمال غربية. درجة تقييم المشروع: حاز على الثهادة الذهبية من نظام مجلس المباني الأمريكي USGBC.

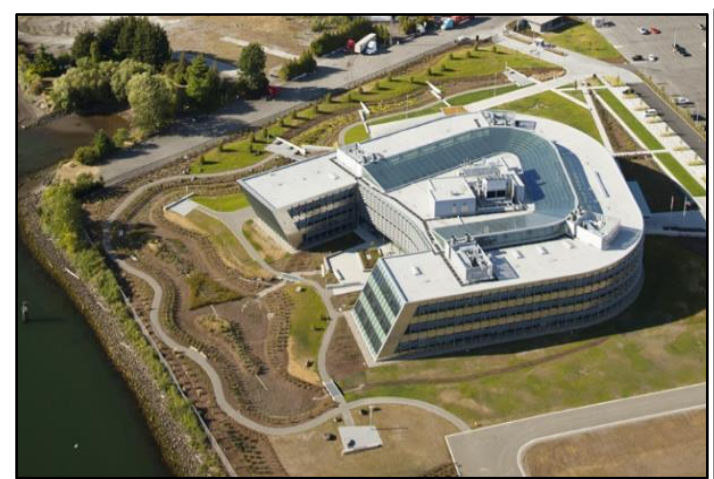

شكل (7) بالية

المركز الفيدرالي بمدينة سياتل بولاية وإشنطن الأمريكية.

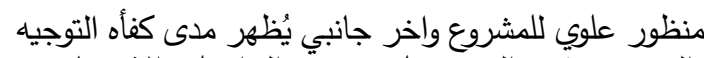

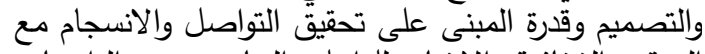

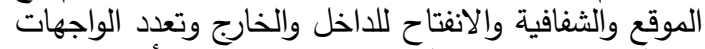

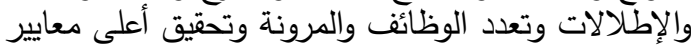
الاستدامة في التصميم الداخلي والمعماري.
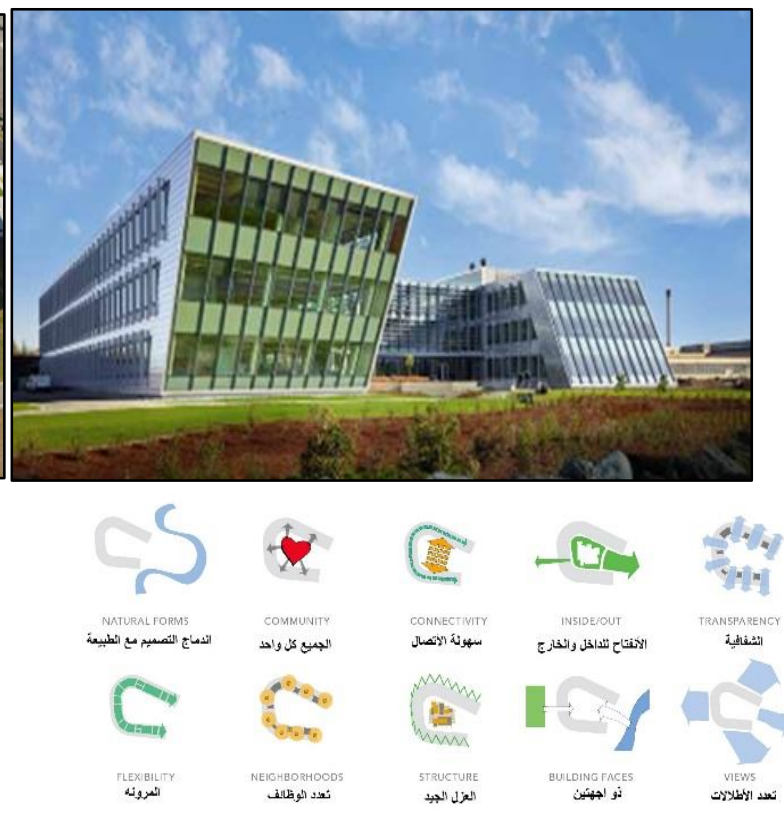

الفكر التصميمي وتوظيف التكنولوجيا بالمشروع

يعد هذا المشروع متكامل من حيث التصميم والبناء والعمارة الداخلية فكان نتيجة لتظافر جهود عدة مؤسسات حكومية منها مؤسسة إعادة الاستثمار والانتعاش الأمريكي (ARRA) حيث طور فريق التصميم والبناء المشروع بأليات وطرق لتحقيق

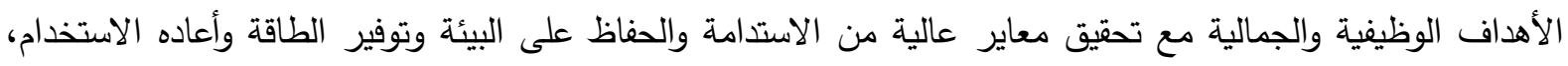
فتميز المشروع بتفاعله مع البيئة والاستجابة لها فأصبح ذو موقع اقليمي مرن ومستدام. 


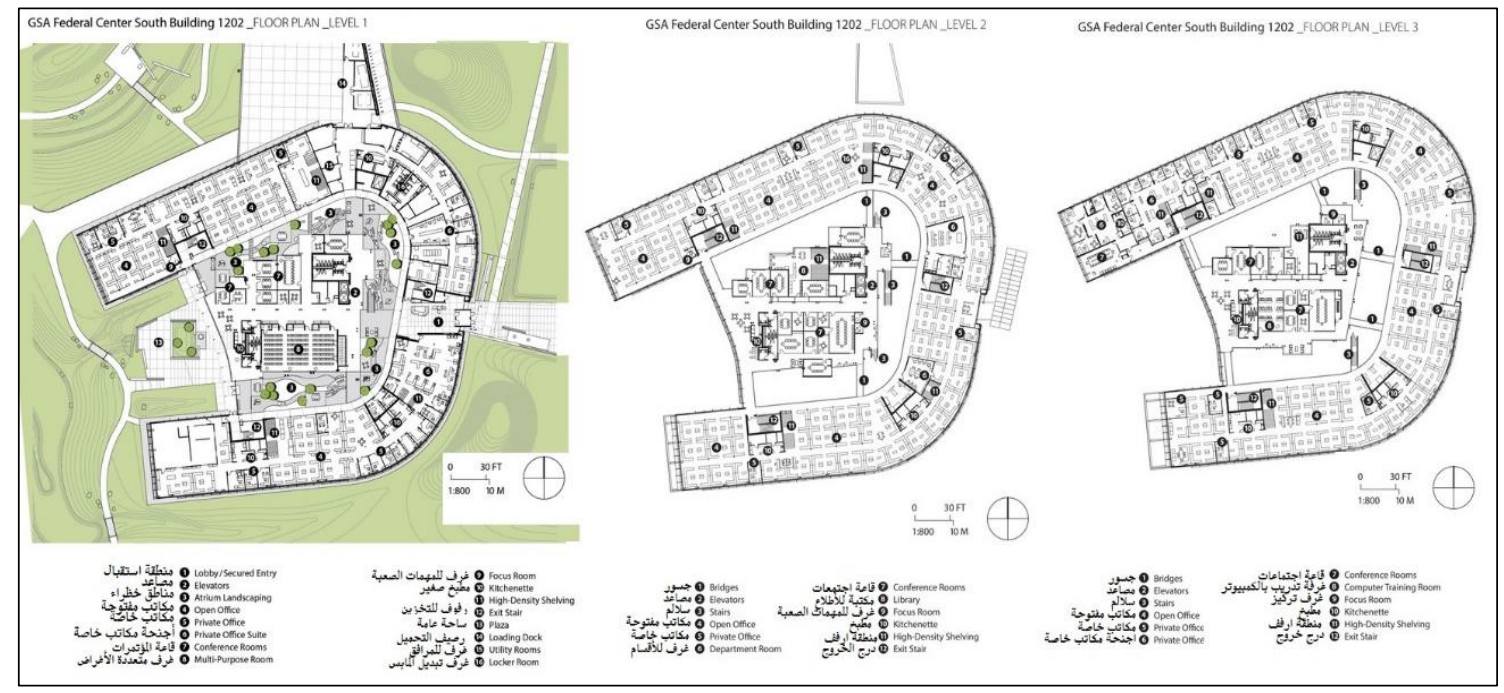

شكل (8)

المسقط الأفقي للدور الأرضي والأدوار المتكرة للمركز الفيدرالي بمدينة سياتل بولاية واشنطن الأمريكية.

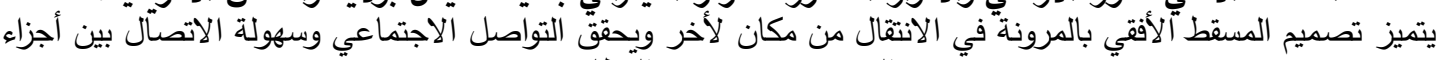
المبنى ويتميز بتعدد الؤظائف.

يعطي الثكل المفتوح والتصميم المرن للمبنى بصمة متكاملة وفي نفس الوقت يخلق هوية ذات أتصال بين جميع الأقسام والعاملين الذين يقطنون المبنى، فحطات العمل تحيط بالجزء المركزي والذي يشكل القلب أو الجزء الحيوي والاجتماعي للمبنى ويضم جميع المصادر المشتركة مثل غرفة الاجتماعات، والمكتبة، والمساحات المخصصة للجلوس لهات لتشجيع التفاعل وخلق أجواء اجتماعية، كما يوفر الارتقاع العالي لهذه المنطقة إطلالة خارجية للجميع. ولتلبية منطلبات الأمن الفيدرالي ومكافحة الإرهاب وكونه مشروع عسكري فأنه صمم ليكون بعيداً عن الأنظار كما لإناء أن الهيكل الإنثائي قد استوفى الثروط الأمنية والبيئية من زلازل وغيره وأخذ في الاعتبار توفير بيئة جذابة للموظفين العاملين

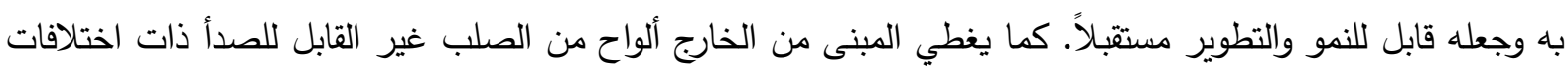

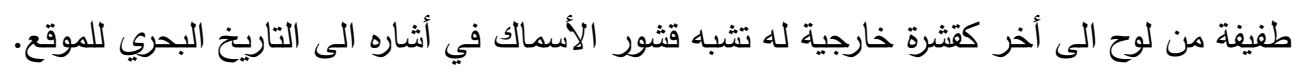

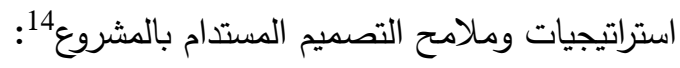
يعد هذا المشروع من مباني المكاتب الأكثر كفاءة في استخدام الطاقة على الصعيد الوطني في أمريكا حيث يوفر الضوء والهواء المتجدد للداخل بشكل منظم من خلال الواجهات الزجاجية والتصميم المرن، ويطبق نظام العزل الحراري والصوتي الجيد، ونظم تحكم لخفض كمية الهواء الخارجي في حالة عدم الحاجة إليه، واستثمار وسائل الطاقة البديلة مثل الطن

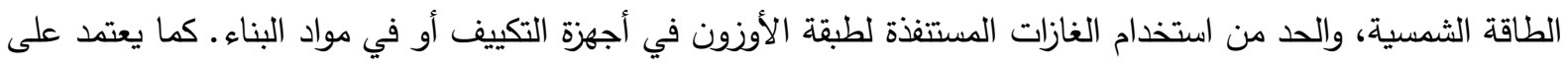
موارد محلية من البيئة يمكن أعادة تدويرها كالخشب والزجاج والصلب والألمنيوم، واستخدام الألوان المناسبة على الواجهات

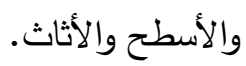



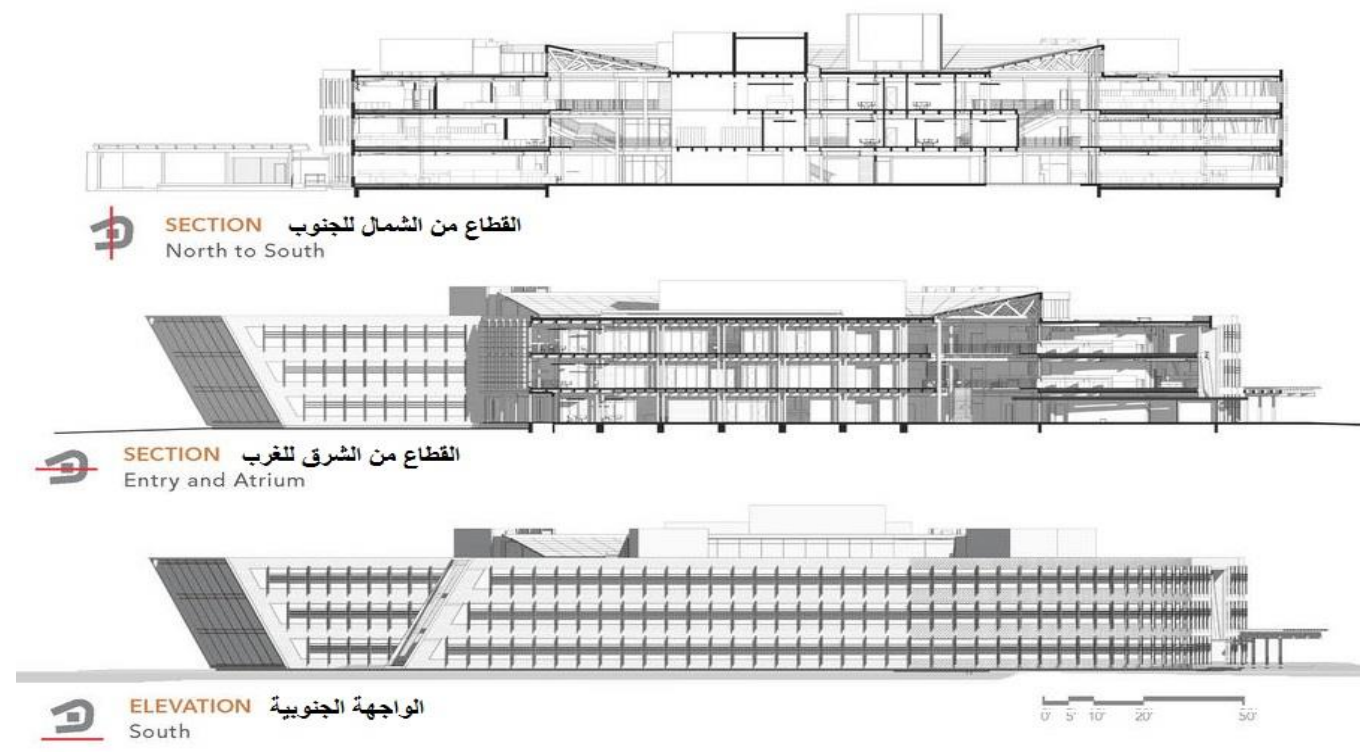

شكل (9) الواجهات الخارجية لمشروع المركز الفيدالي الجنوبي 1202 بولاية والشنطن الأمريكية.

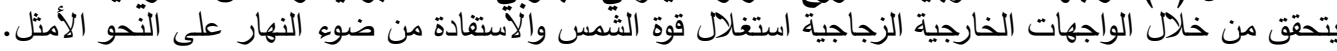
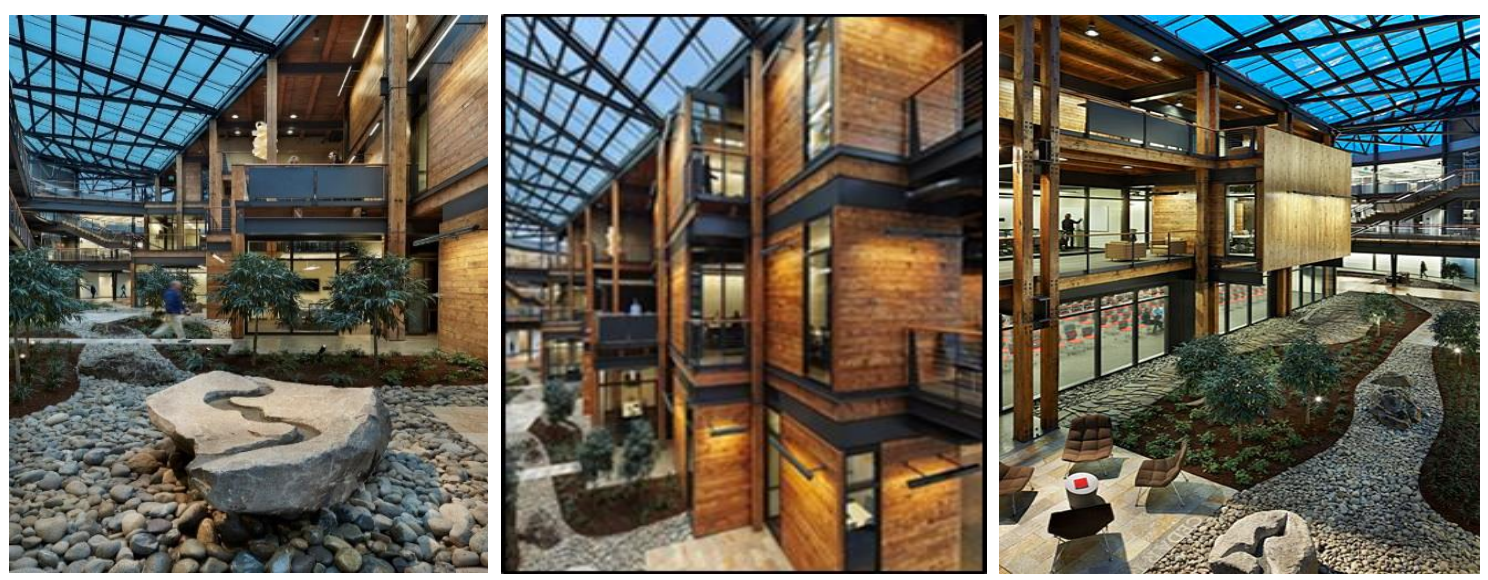

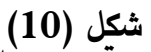

تصميم الحرم الاخلي الذي يعزز الهوية الاجتماعية ويدعم الزرابطة الغريزية بين الأنسان والأنظمة الطبيعية. تكامل النظم البيتيه والتكنولوجيه آلموظعل في المتروع:

صُمم كل جانب في المبنى لتحقيق أداء عالي واستجابة مباشرة وايجاد بيئة عمل ذات أداء عالي مع معايير مستدامة، ويُعد المبنى من أوائل المشاريع التي استخدمت أكوام التركيب الإنثائي (Structural Piles) للتدفئة، والتبريد باستخدام الحرارة الأرضية (Geothermal Heating)، بالإضافة الى وجود خزانات للتخزين الحراري. كما تم تطوير منتجين جديدين

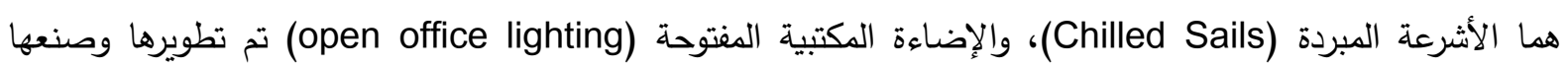
خصيصاً لهذا المشروع وذلك للوصول الى أهداف عالية ومحددة في الحفاظ على الطاقة.

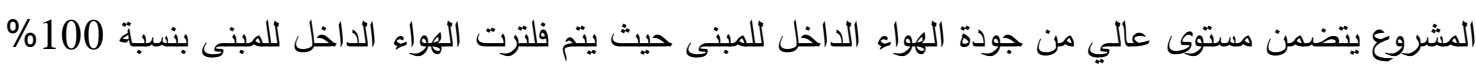
بفلاتر تحت أرضية، كما تم حل مشكلة المياه الجارفة من السيول في حالة حدوث عواصف فيتم ضخ المن المياه الناتجة من العواصف الى شبكة المياه الخاصة ومن ثم فلترتها وتتقيتها لضمان عدم حدوث تلوث اثناء استخدامها. كما تساعد الألواح الأرضية لمكاتب العمل على نفاذية أكبر قدر مدكن من الضوه الطبيعي الخارجي للوصول الى محطات العمل وذلك لتقلتيل وترشيد استخدام الضوء الصناعي وبالتالي ترشيد استخدام الطاقة المرتبط بها. 


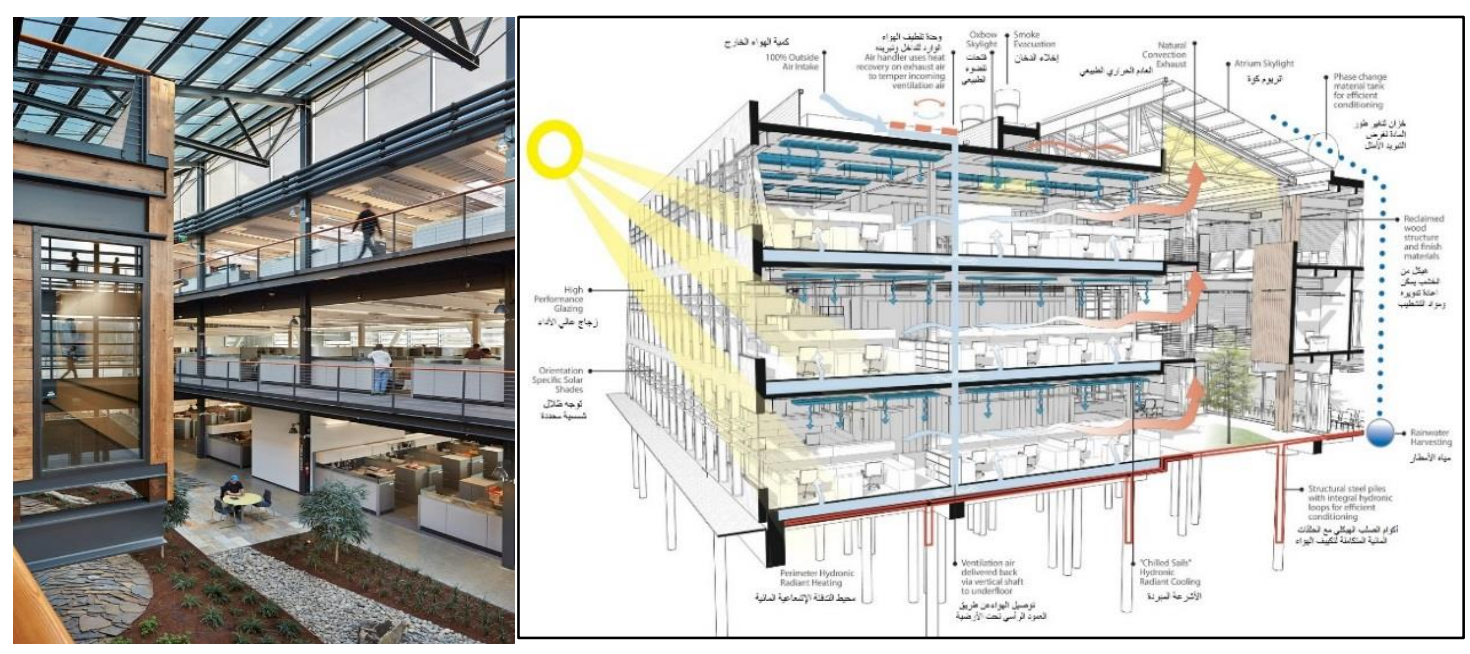

شكل (11) المعالجات المتبعة للإضاءة الطبيعية والتهوية الطبيعية والعزل الجيد والاستفادة من مياه الأمطار.

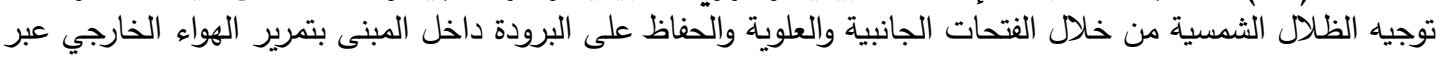
قنوات الترشيح ليتدفق من خلال الطوابق.
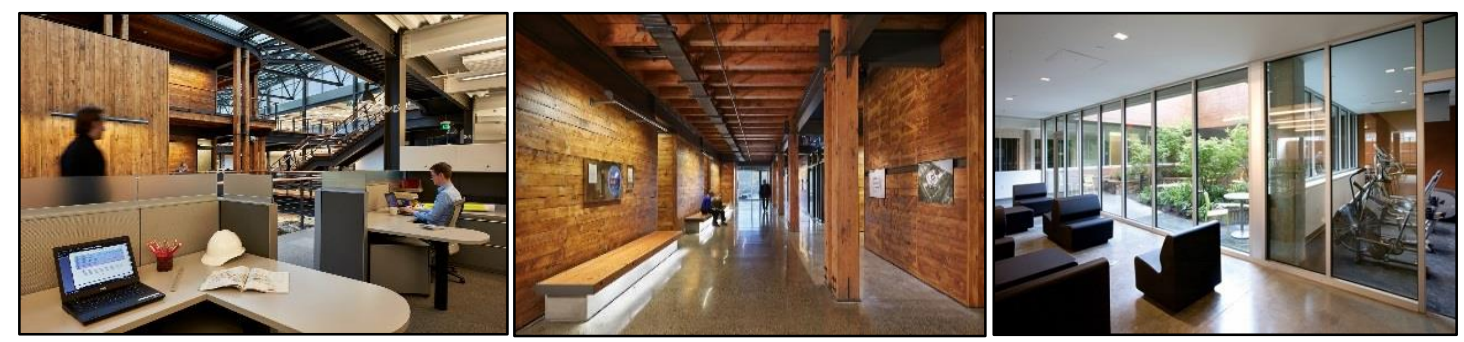

شكل (12) التصميم الداخلي لبعض الفراغات الوظيفية بمشروع المركز الفيدرالي الجنوبي 1202 بولاية واشنطن.

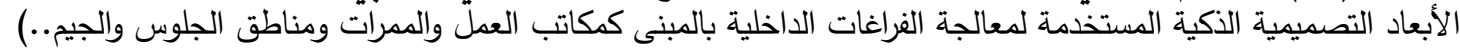

شكل (13)

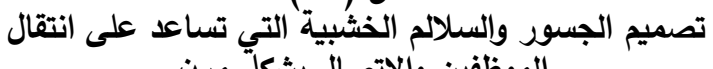

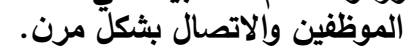
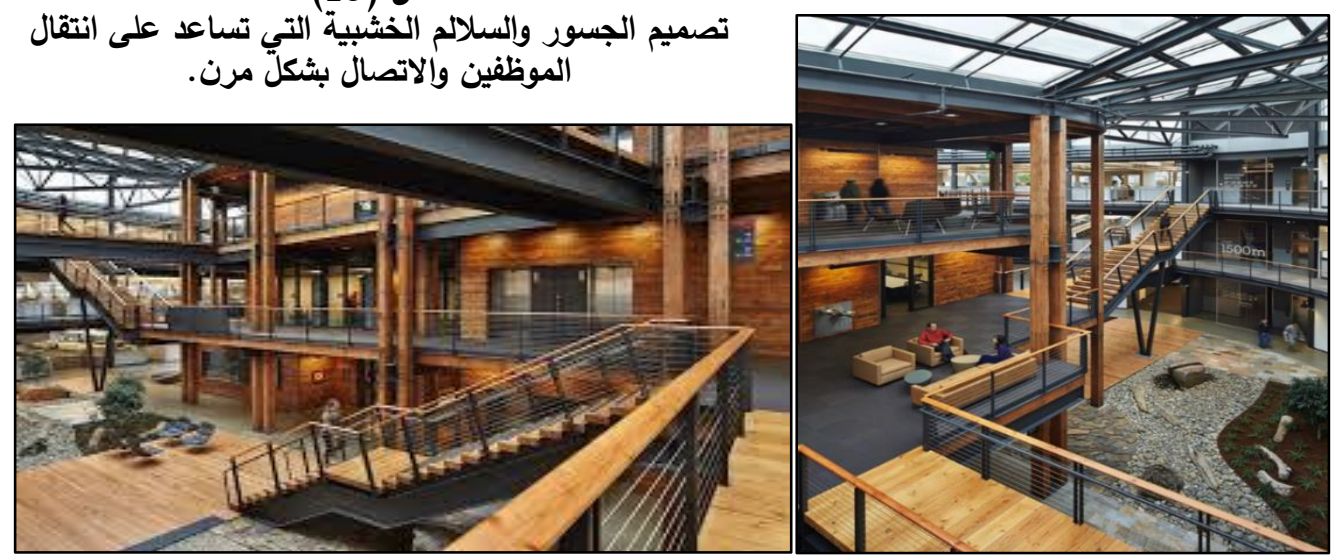

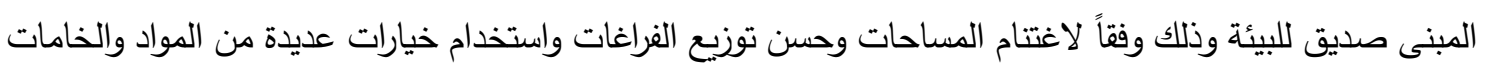

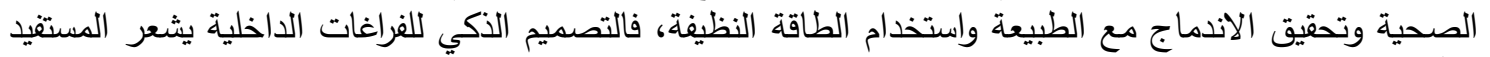

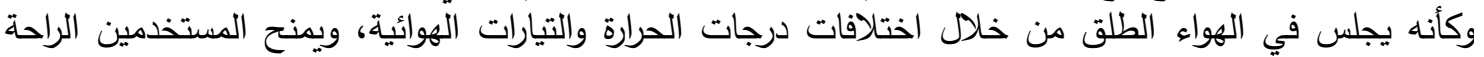

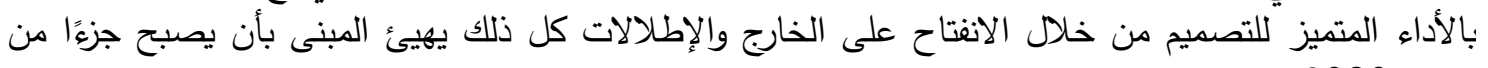
تحدي 2030. 

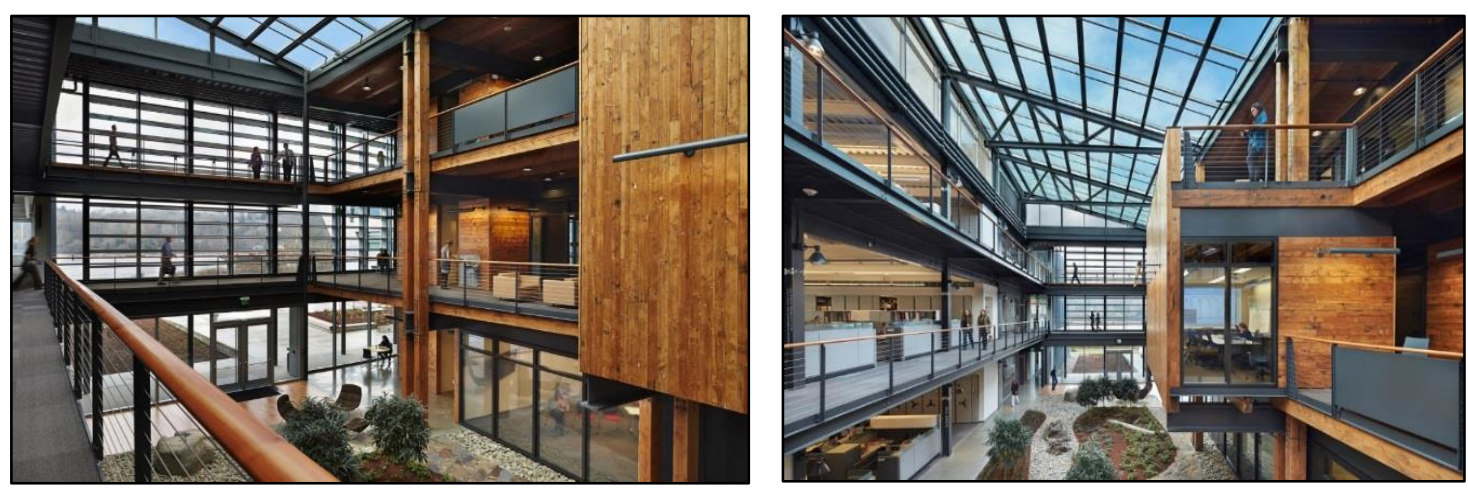

شكل (14) نمط توزيع الحيزات الفراغية الاخلية وتحقيق الانفتاح الاخلي والخارجي من خلال الأسطح.

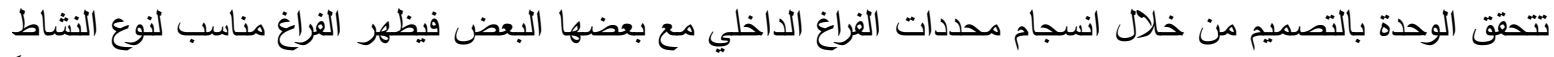

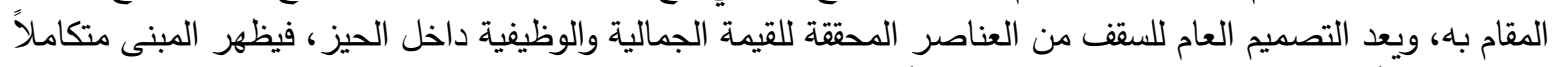

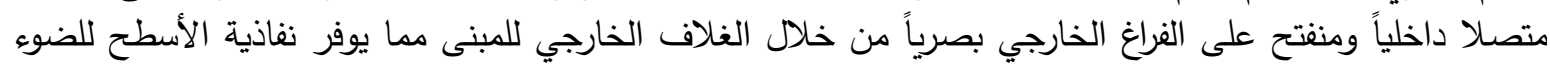

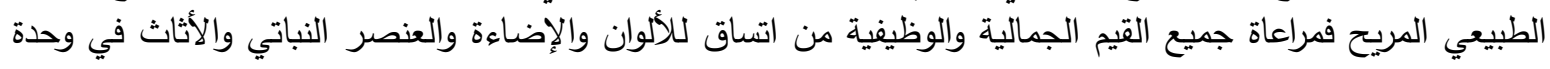

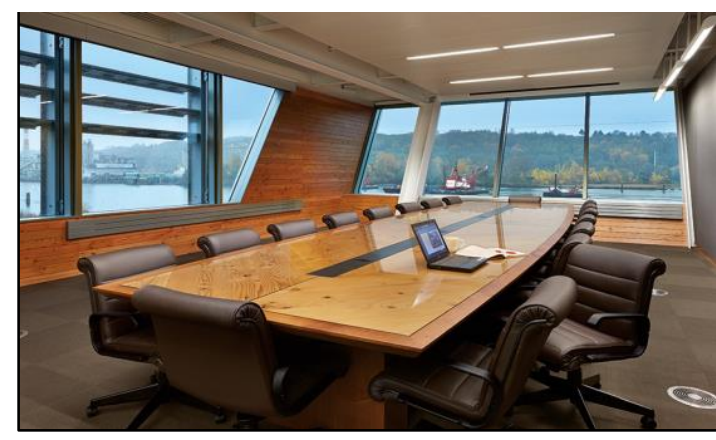
متكاملة تكفل تحقيق الراحة للمستخدمين.

شكل (15) يظهر بالتصميم امكانيات التكنولوجيا الحديثة للأثاث، ونظم توزيعه ودوره في تحقيق الوظائف بأعلى كفأه في الأداء لخدمة النواحي الوظيفية والبيئية معاً.

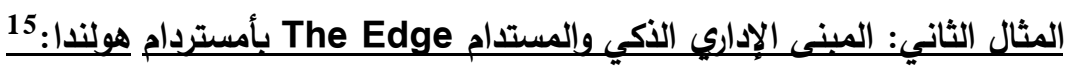
الموقع: في وسط حي الأعمال بمدينة أمستردام في هولندا. المساحة الإجمالية: 40 ألف متر مربع - وتكلفة المشروع: 74 مليون يورو.

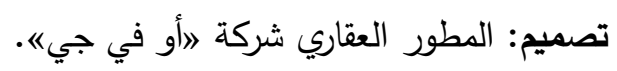

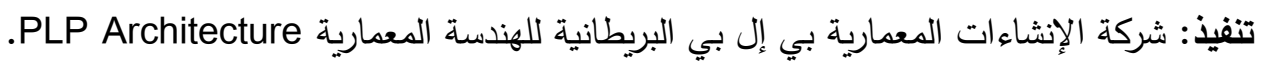

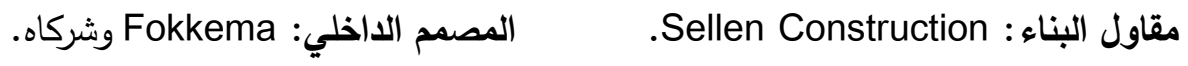
تنفيذ المشروع: تم البدء بتتفيذه 2010 وتم الانتهاء منه في 29 مايو 2015م. نوع المبنى: اداري.

درجة تقييم المشروع: حاز على شهادة BREEAM بمعدل 98.4 بالمائة، وهو أعلى مستوى منذ أن بدأت مؤسسة أبحاث البناء BREEAM بالمملكة المتحدة برنامجها الخاص بالتئييم البيئي. 

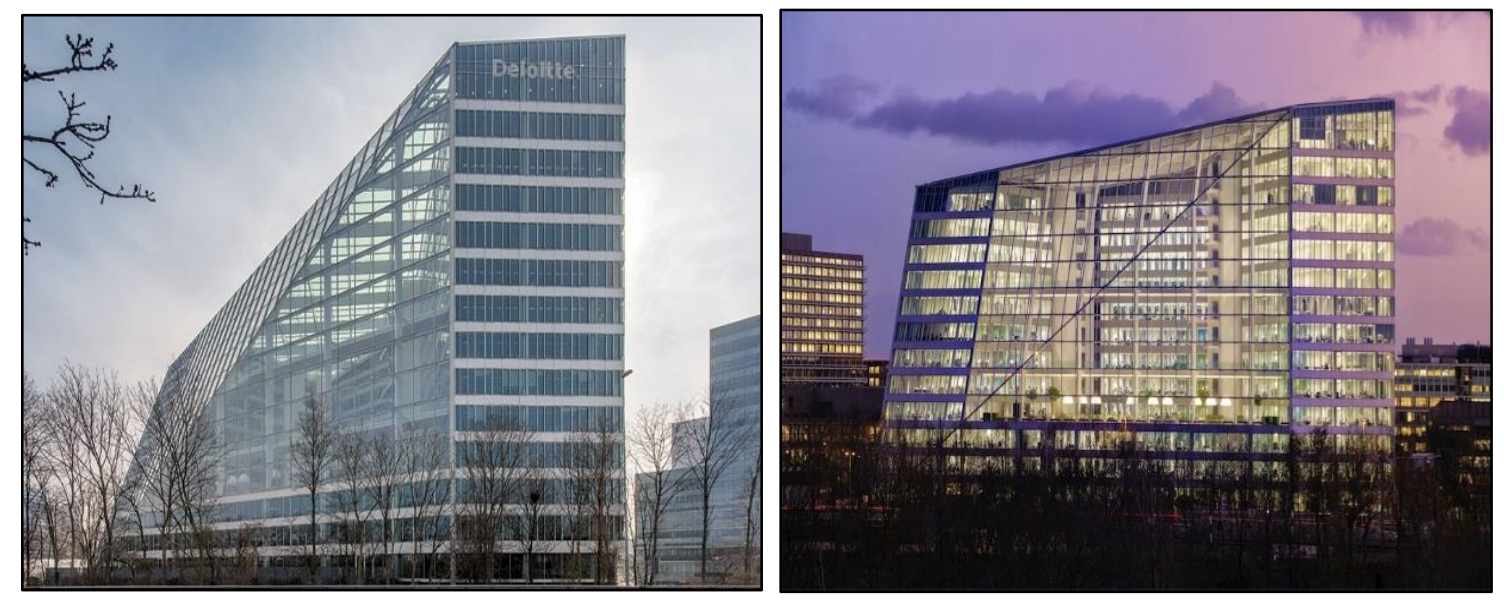

شكل (16) منظر أمامي وجانبي للمبنى المستدام الذكي The Edge بأمستردام هولندا.

يمتاز المبنى بواجهاته وجدرانه الزجاجية الثفافة وتصميمه العصري، تبلغ واجهة المبنى الزجاجية الخارجية 47 مم

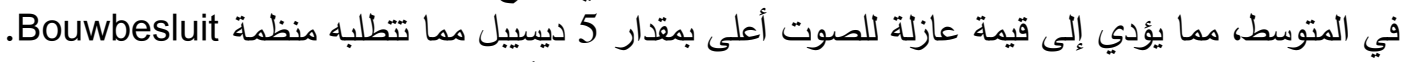

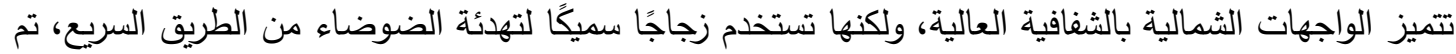
تصميم الجدران الداخلية لتكون عازلة للصوت تهاتيات
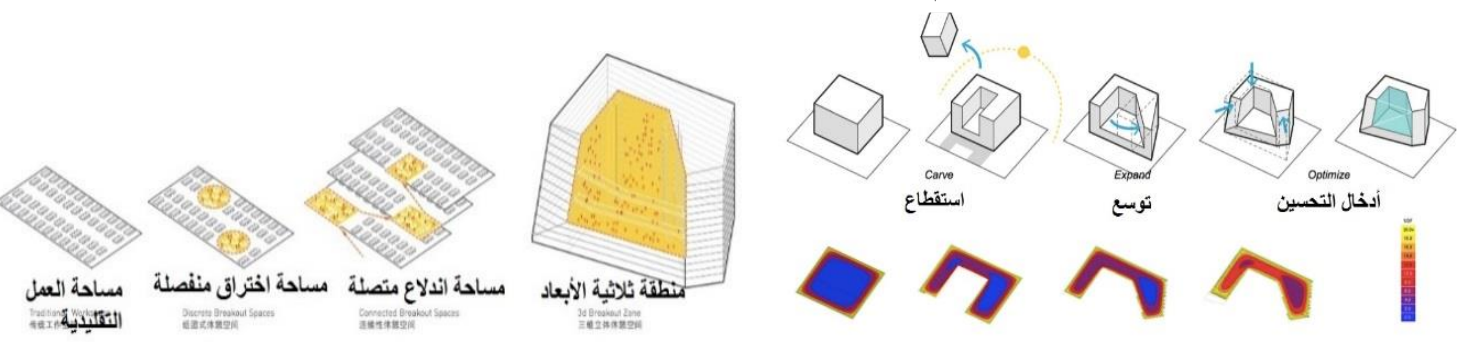

شكل (17) التطور التدريجي لثكل كتلة مبنى The Edge وتوجيهه وتصميمه الخارجي.

استراتيجيات وملامح التصميم المستدام بمبنى The Edge الإداري:

يعد المبنى من أذكى المباني بالعالم وصنف بأكفائها استدامة حيث أرادت شركة 》ديلوويته تعزيز عملياتها في مبنى يعمل كمحفز للانتقال إلى العصر الرقمي فوظفت التكنولوجيا الذكية وأنظمة التحكم عن بعد بالمبنى. يحظى المبنى بتوجيه

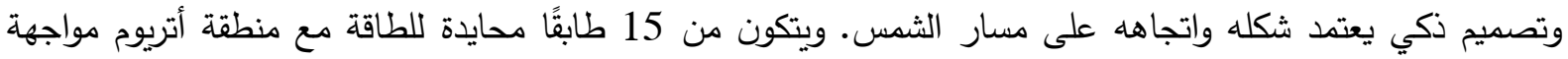
للثمال تغطي المبنى بارتفاع 58 م مع شكل وتوجيه ملهم، مما يجعل بيئة العمل مفتوحة مع الضوء الطبيعي حتى في الأيام الرمادية، بينما تحمي الألواح الثمسية التي على الواجهة الجنوبية مساحات العمل من الثمس. الجدران الحاملة إلى الجنوب لهب والشرق والغرب بها فتحات أصغر لتوفير الكتلة الحرارية والتظليل وللتهوية.

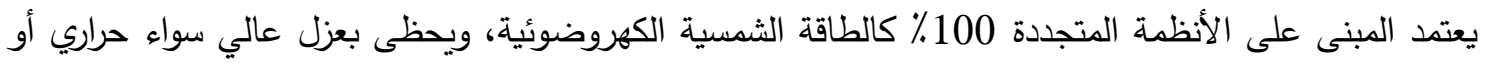
ضوئي أو صوتي. كما صُمم لله نظام تهوية طبيعية وميكانيكية مثلى، ويعتمد على نظام لتخزين الطاقة الحرارية للمياه الجوفية للتدفئة والتبريد حيث يولد جميع الطاقة اللازمة لتدفئة وتبريد المبنى. ويتحقق به استفادة ناجحة من مياه الأمطار ومعالجتها واستخدامها لريّ التراسات الخضراء في الأتريوم ومناطق الحدائق الأخرى المحيطة بالمبنى. كما أن جميع المواد والموارد المستخدمة طبيعية بنسبة 95 ٪ ويمكن أعادة تدويرها أو تصنيعها. فالخشب المستخدم في The Edge هو مصرح من مجلس الإثراف على الغابات. 


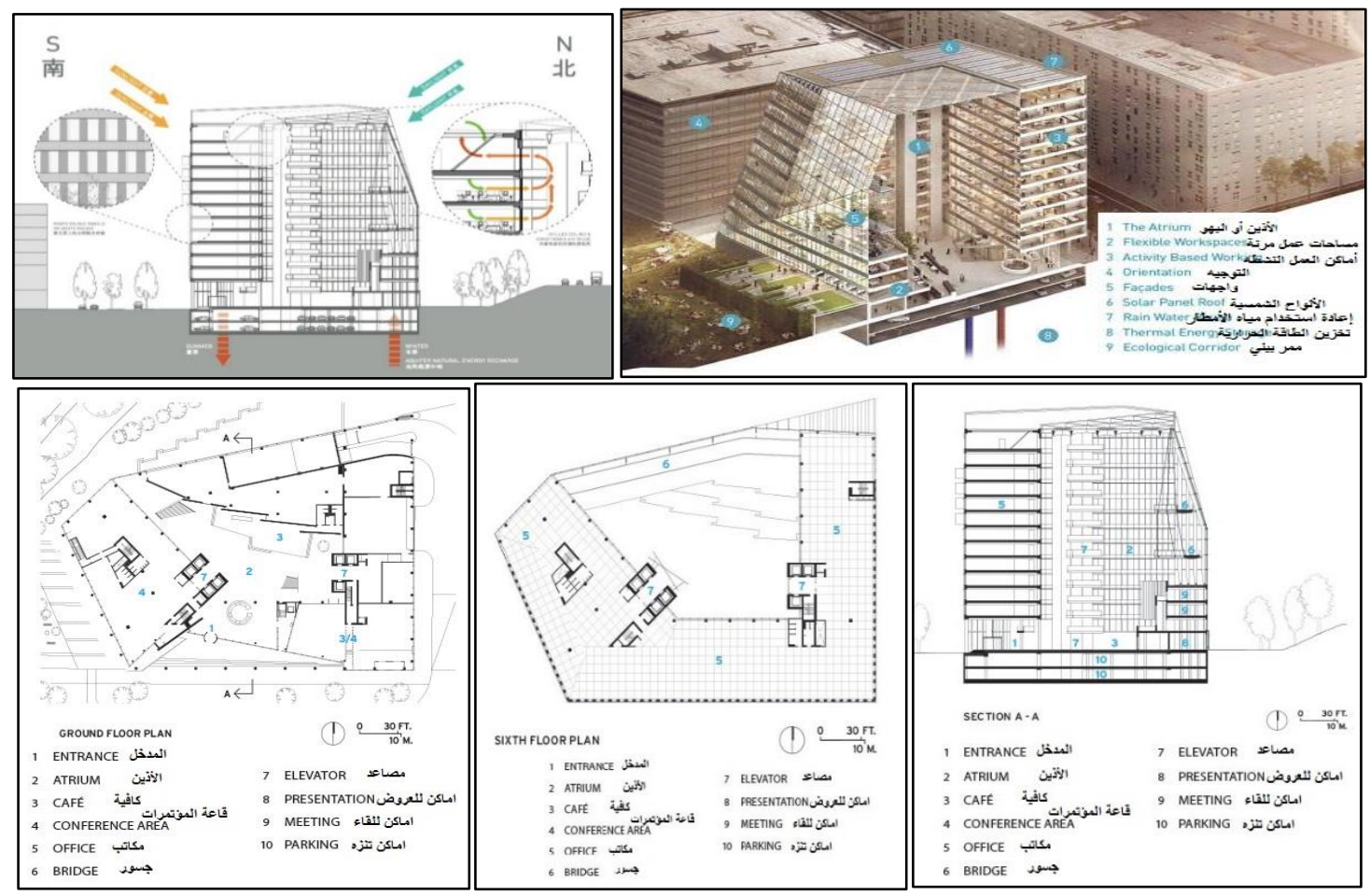

شكل (18) منظور وقطاع لأحدى الواجهات ومسقطين أفقية توضح أهم فراغات العمل والخذمات وتوزيعها بالمبنى.

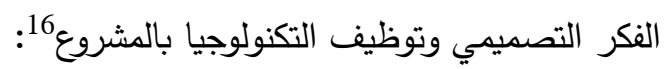

يقترح هذا المبنى طريقة جديدة للعمل باستخدام تكنولوجيا المعلومات لتثكيل طريقة عمل الناس وكذلك المساحات التي يعملون فيها فيبدأ اليوم التقليدي في المبنى مع تطبيق طورته الثركة القاطنة به حالياً ديلويت، فمن اللحظة التي يستقيظ فيها الموظف يصبح متصلاً بشكل تلقائي بالتطبيق الذي ينسق جدوله العملي، ويتعرف المبنى على سيارته بمجرد وصولها ويوجهها إلى مكان متاح بالموقف، ويساعده على إيجاد مكتب متاح للعمل عليه، وذلك لأن The Edge لا توفر مكتب

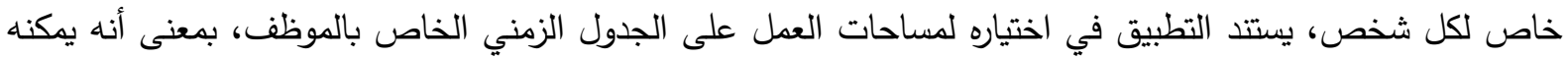

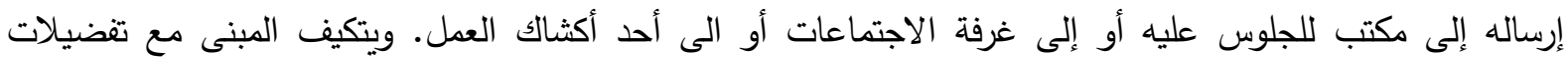
المستخدمين للإضاءة والتدفئة عبر تطبيق الموبايل، ويسمح لهم تحديد موقع زملائهم والعثور على مكاتب خالية. فيختار الموظفون بفعالية البيئة والمزاج والغلاف الجوي الذين يرغبون في العمل به من أجل مهام مختلفة على مدار اليوم.
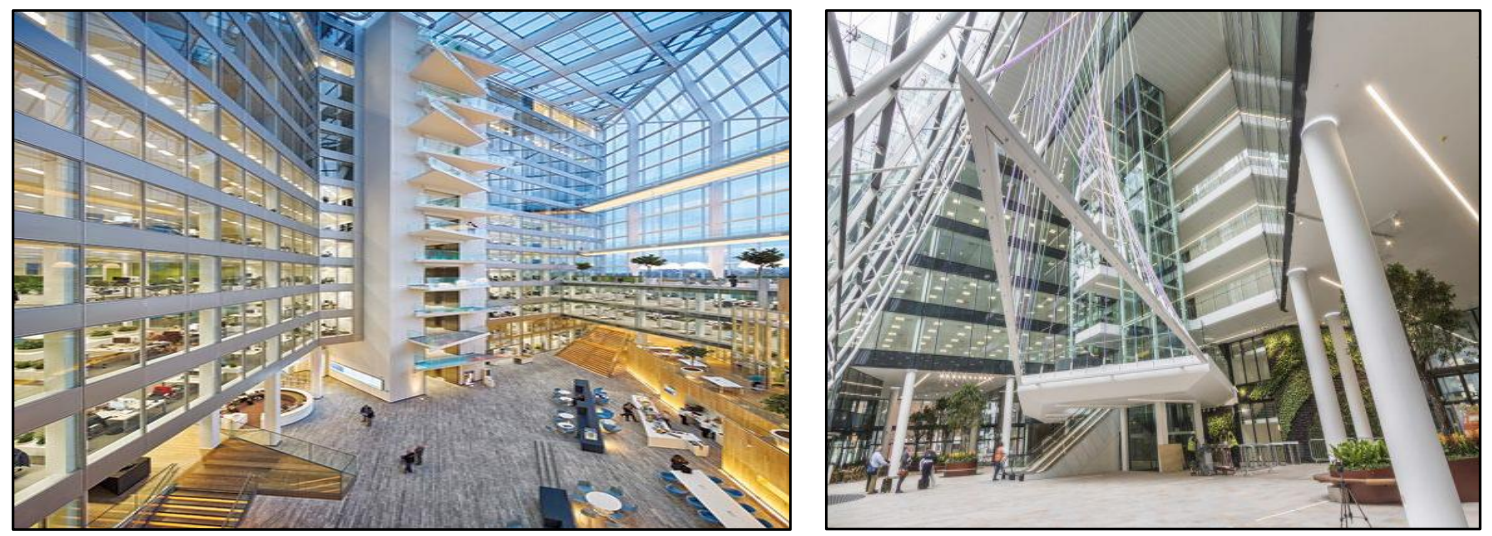

\section{شكل (19) المدخل الرئيسي للمبنى The Edge والبهو الاخلي.}

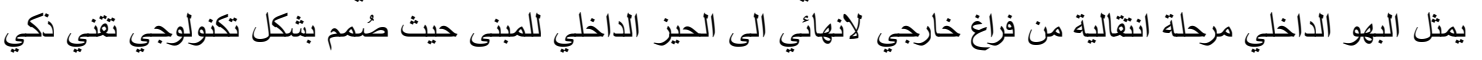

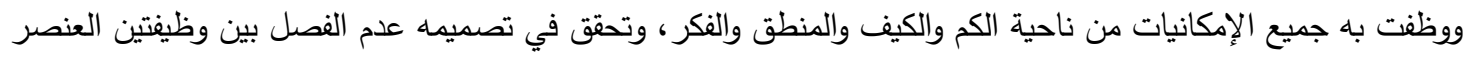

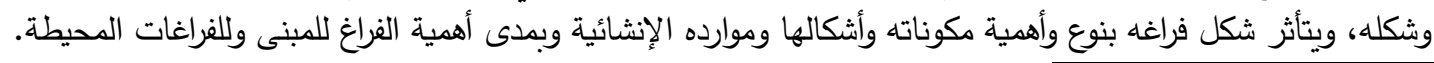

16 http://www.buildup.eu/fr/node/51248. 


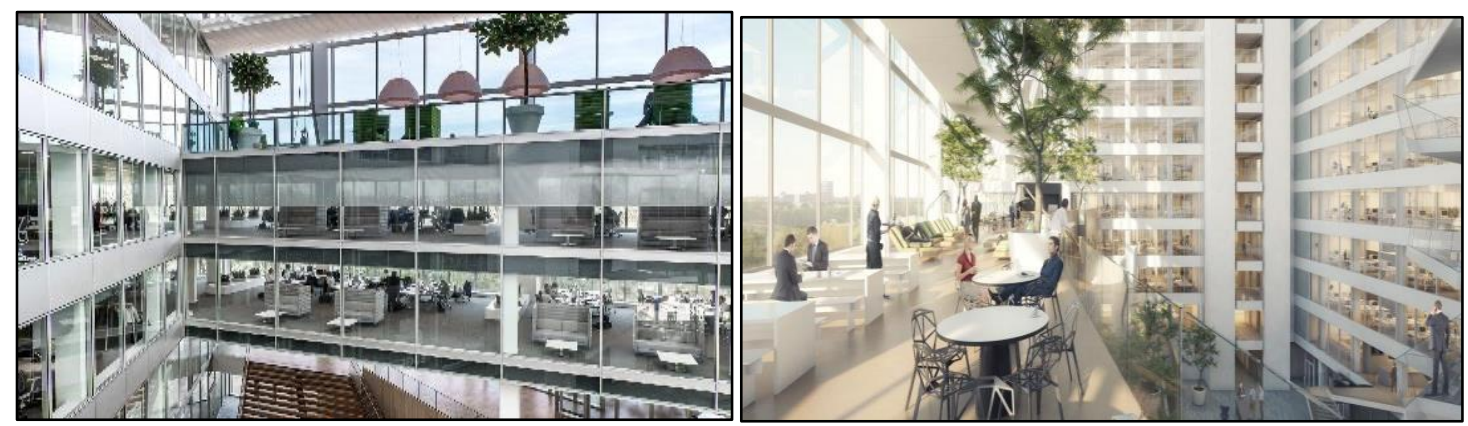

شكل (20) إطلالات متنوعة لمنطقة الأتريوم المواجهة للشمال.

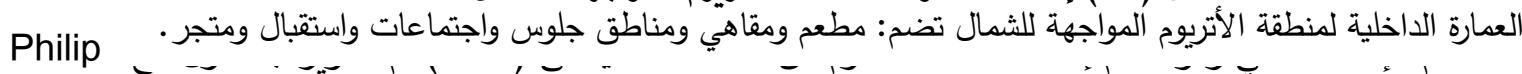
والذي ينتج استهلاك للطاقة بمقدار W/m2 بد/لاً من 8 W/m2 التقليدي، ويحتوي النظام على أجهزة استشعار تستشعر

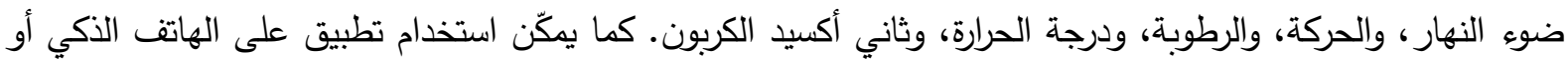

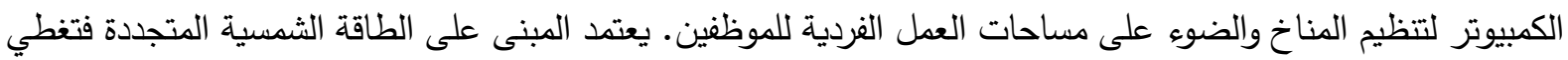
الألواح سقفه والواجهة الجنوبية، وجزء أخر على سطح جامعة أمستردام ويحقق المبنى اكتفاء ذاتي من الطاقة. كما أنا نظام

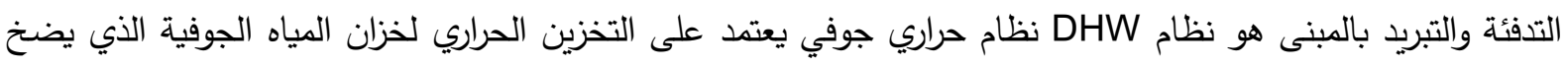
المياه الباردة/الدافئة إلى داخل المبنى وخارجه حسب المناخ الداخلي أو الخارجي. ونظام التهوية طبيعية تعتمد على ألواح النوافذ الأوتوماتيكية القابلة للفتح في الواجهة الجنوبية أما التهوية الميكانيكية فتعدد على المبادل الحراري المزدوج التدفق.
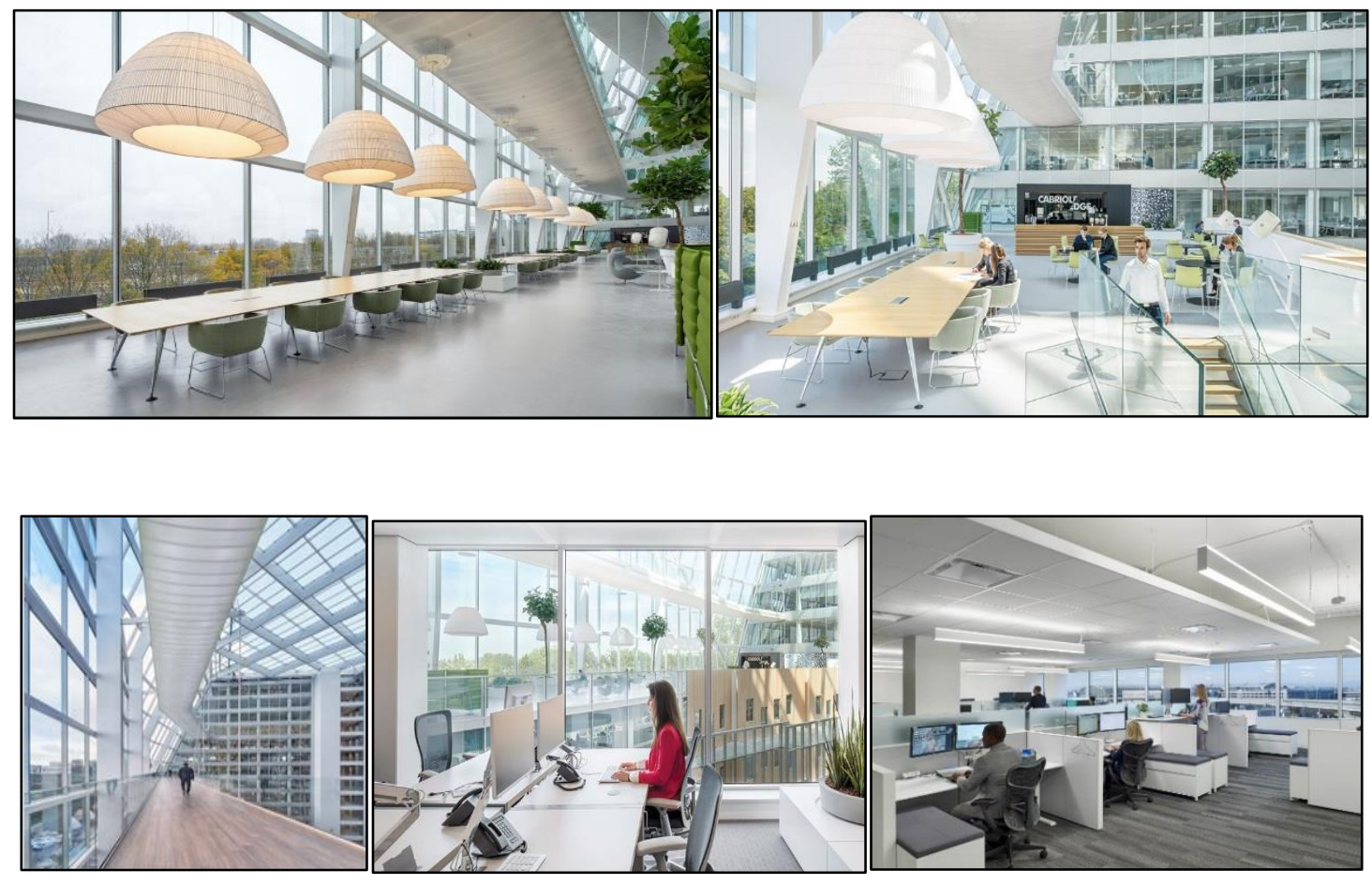

شكل (21) التصميم الداخلي لبعض فراغات العمل المخصة بمنطقة الأتريوم المواجهة للشمال. 

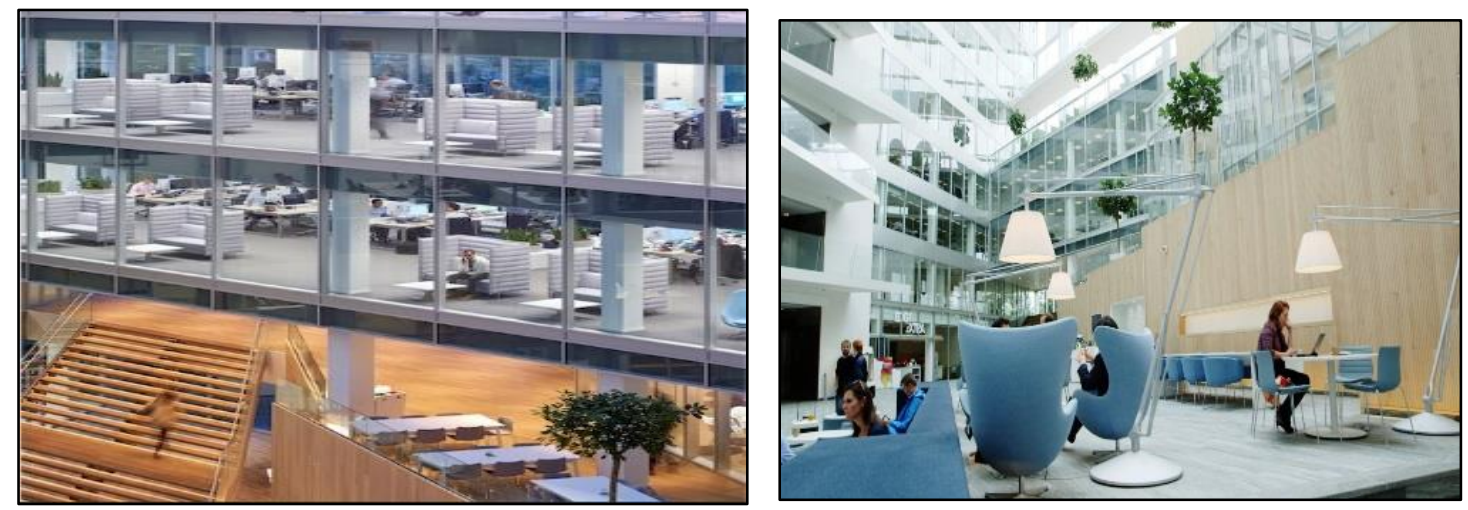

شكل (22) تصميم الفراغات الداخلية العملية كمكاتب الجلوس والمكاتب الدائمة وغرف تركيز، إلى جانب العديد

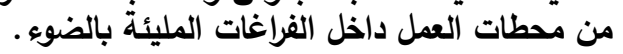

المثال الثالث: مشروع Manitoba Hydro Place المستدام بمقاطعة مانيتوبا الكندية:

Portage Avenue 360 الموقع: وينيبيغ كبرى مدن مقاطعة مانيتوبا الكندية

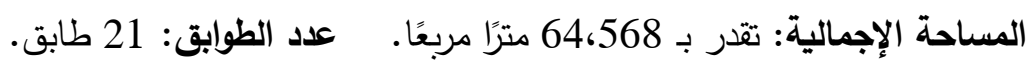

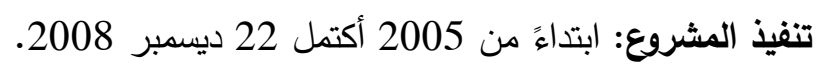
تكلفة المشروع: 278 مليون دولار كندي. المالك:Manitoba Hydro. نوع المبنى: مبنى مكتبي - مشروع حضاري. تصميم: المهندس المعماري Kuwabara Payne McKenna Blumberg Architects مع المهندس المعماري Smith .Carter

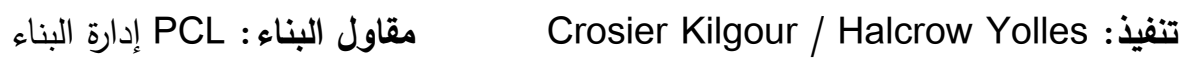
درجة تقييم المشروع: حاز على شهادة LEED Platinum بلاتينية وهو أعلى مستوى تقييم لنظام مجلس المباني الأمريكي

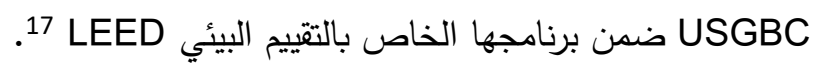
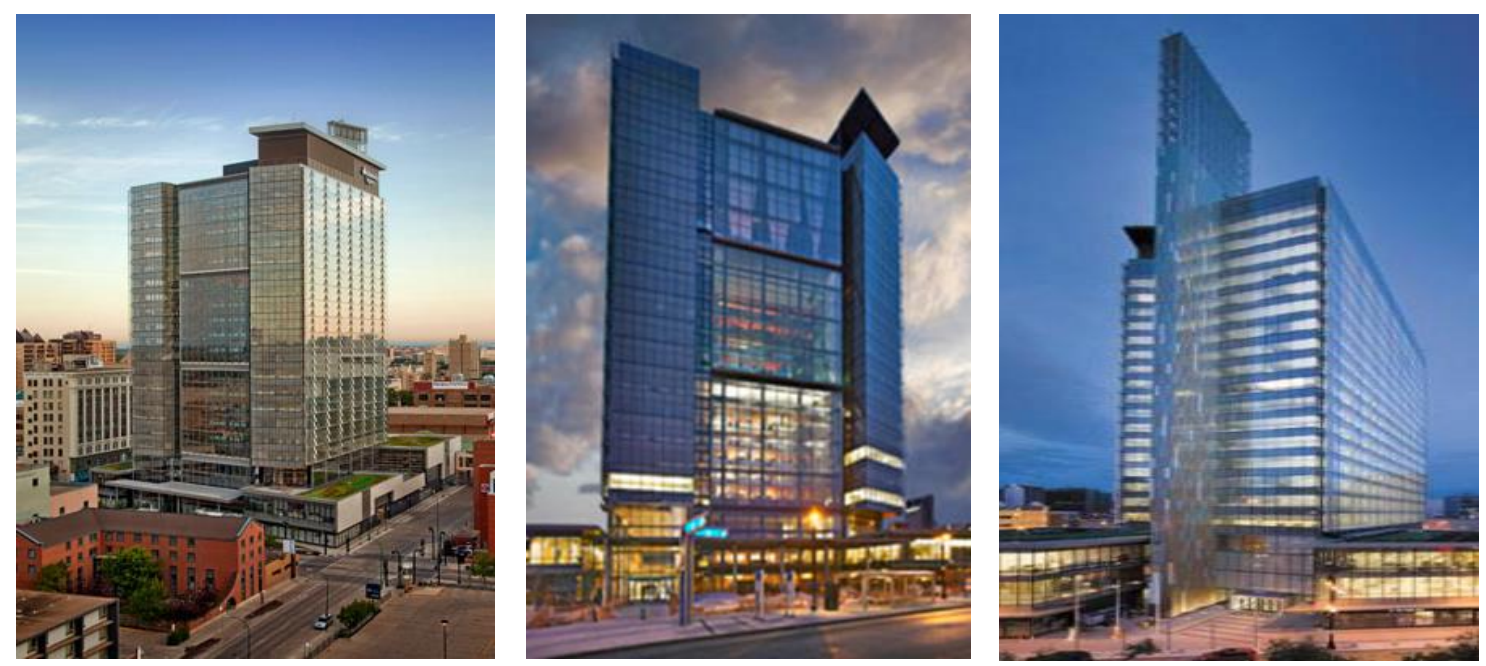

شكل (23) منظر خارجي أمامي وجانبي وخلفي لمبنى شركة Manitoba Hydro المستدام.

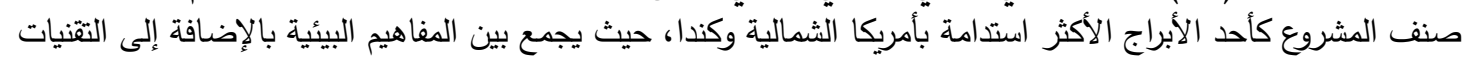

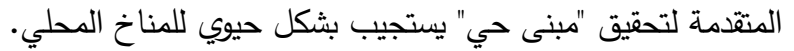
أهداف المشروع: تمثلت اهدافه والمتقق عليها من قبل فريق التصميم والمالك في الاتي: • إزالة التجسير الحراري. 
• • إنشاء حواجز حرارية وعزل جيد.

• • أنثاء أنظمة ميكانيكية عالية الكفاءة.

• • الاستفادة من الإضاءة والتهوية الطبيعية.

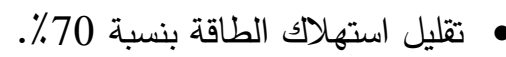

الفكر التصميمي المستدام وتوظيف التكنولوجيا بالمبنى Manitoba Hydro Place:
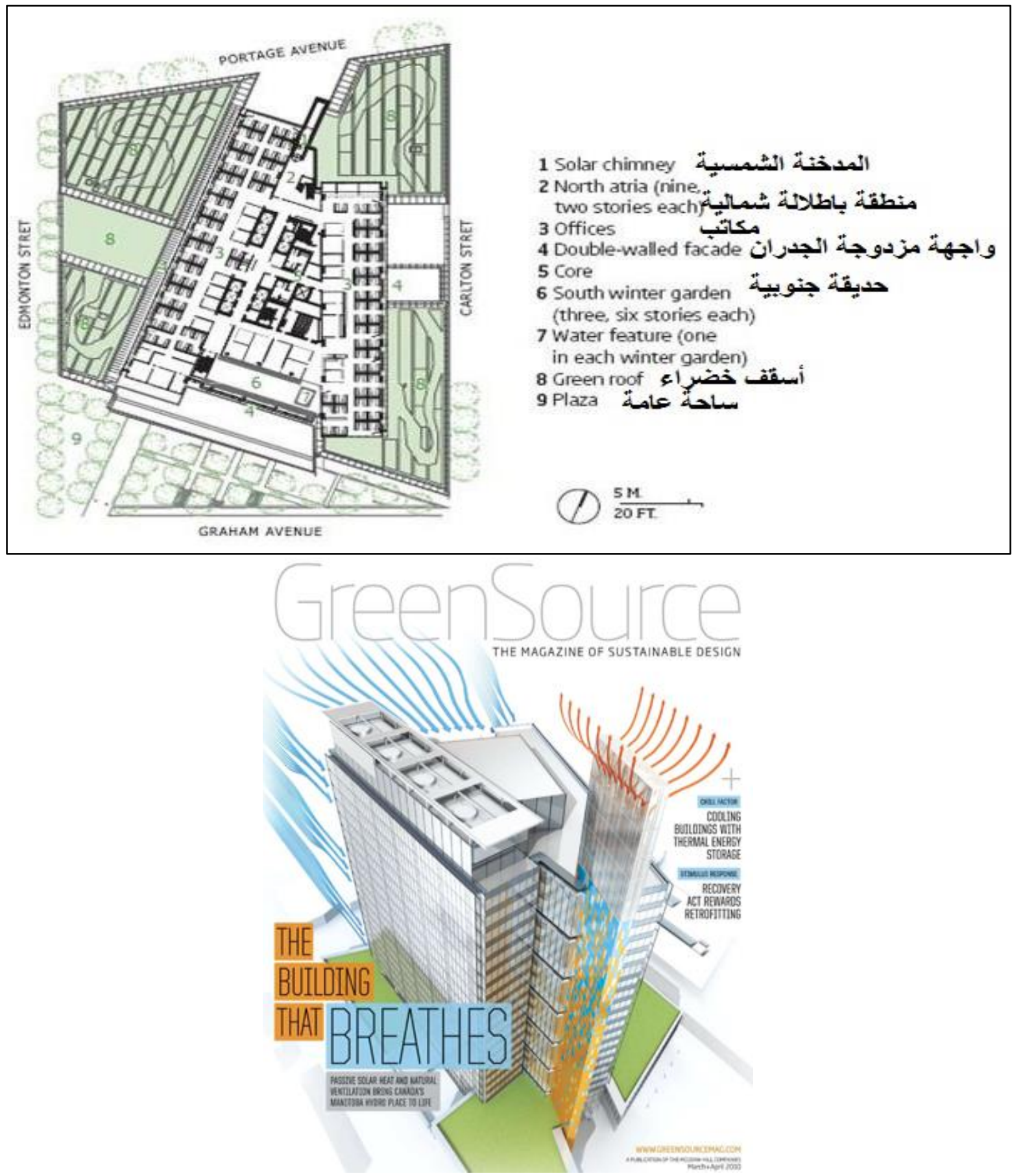

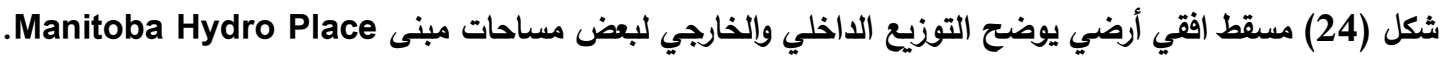

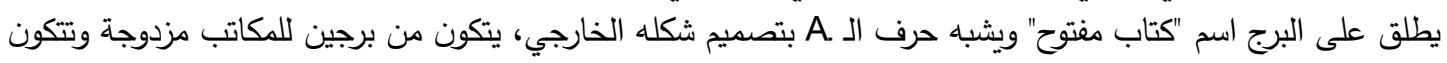

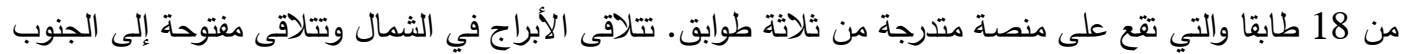

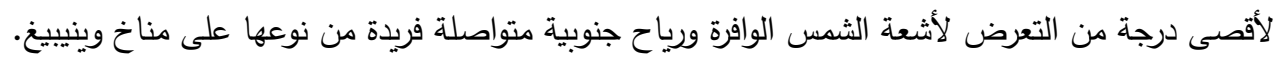




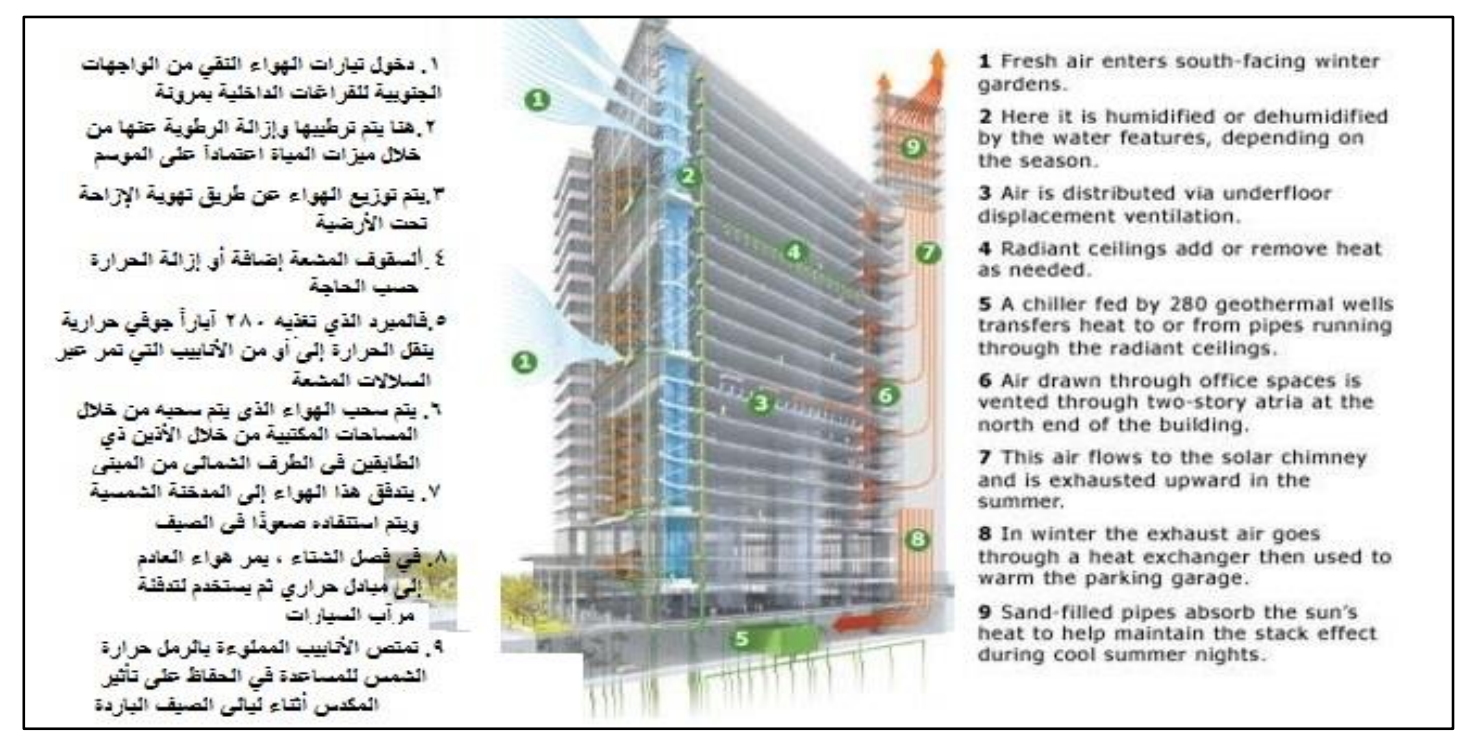

شكل (25) المعالجات المناخية للفراغات الاخلية بمبنى Manitoba Hydro Place.
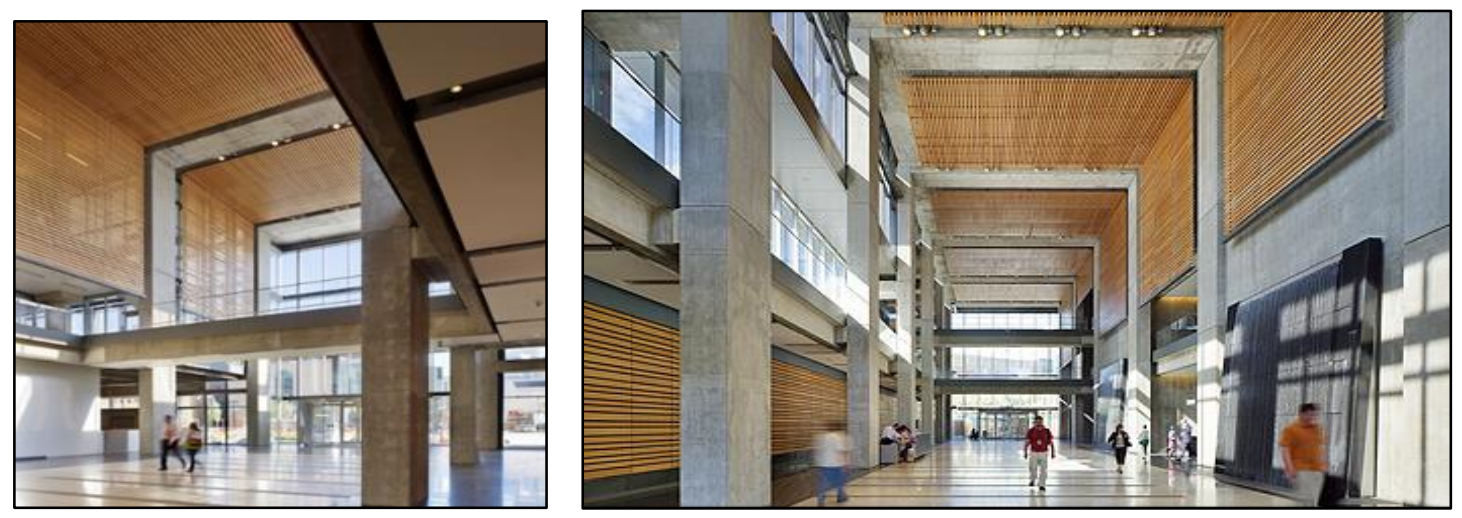

شكل (26) التصميم الداخلي لأحد المداخل وممرات الحركة يتضح من خلالها كفأه التصميم وإختيار مواد التشطيبات.
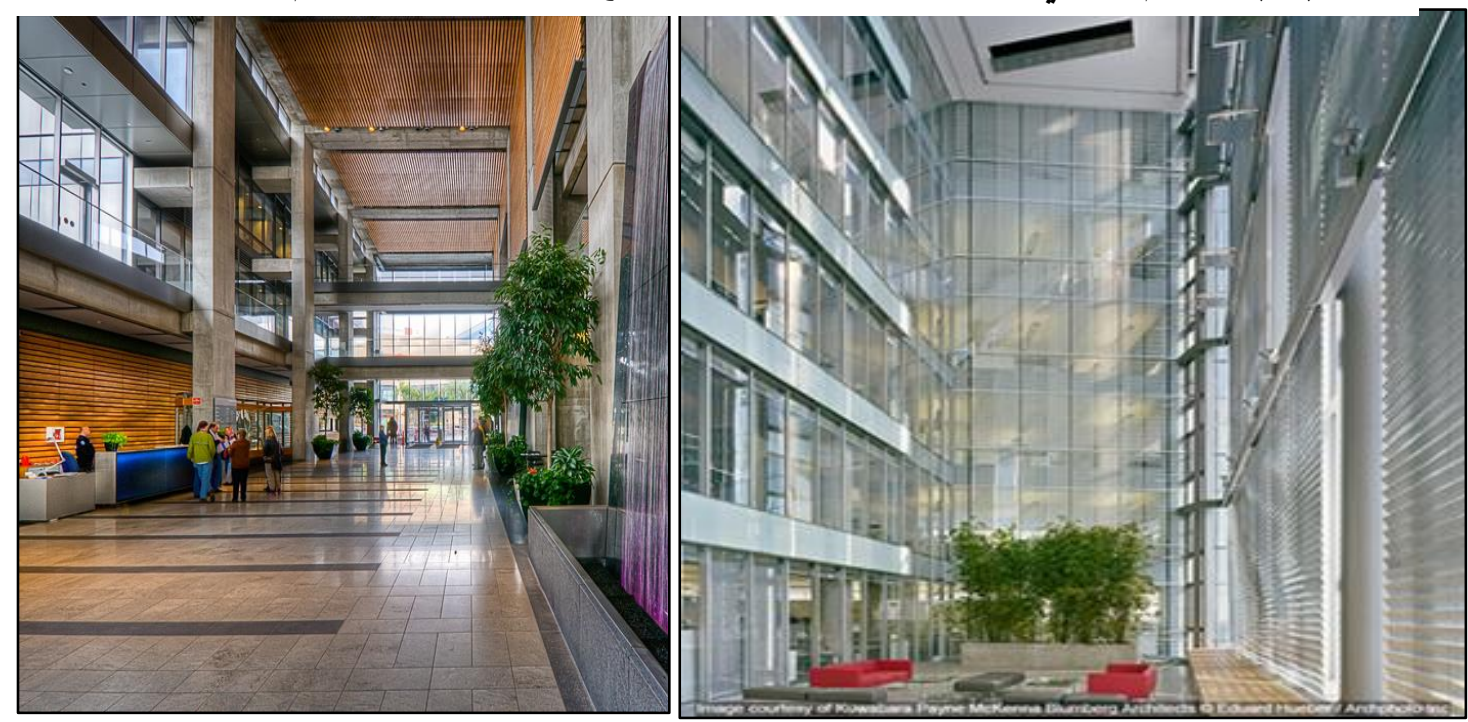

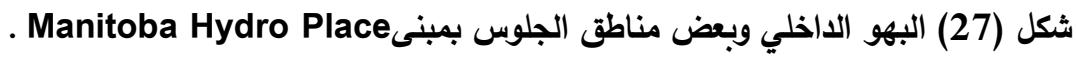

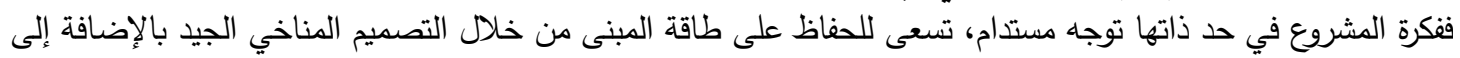

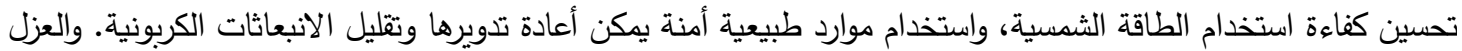
الصوتي والمناخي والضوئي المدروس بالمبنى. 


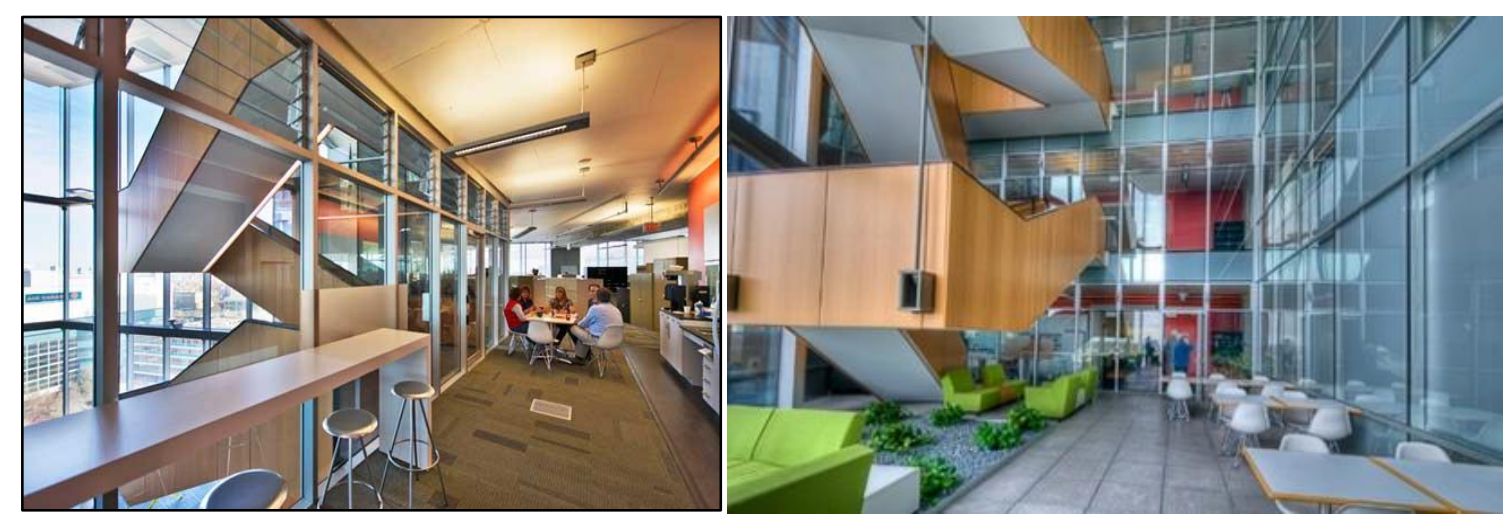

شكل (28) توظيف مبدئ التصميم المتكامل والأساليب المستدامة بالفراغات الداخلية وظيفياً وتثكيلياً.

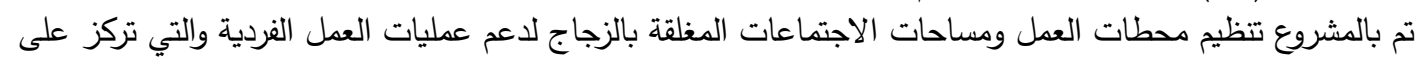

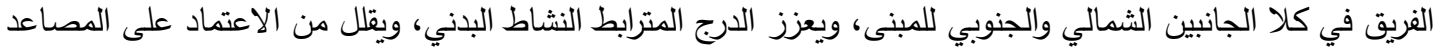
ويوفر فرصًا للتفاعل بين الأقسام.

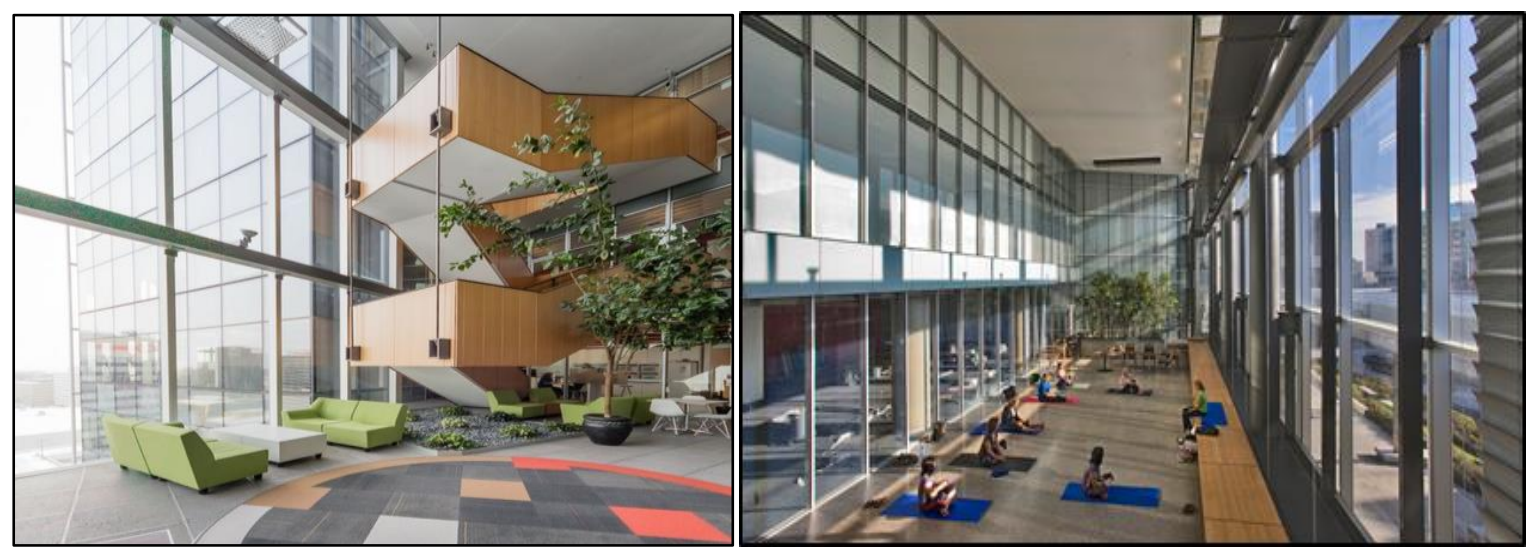

شكل (29) الفراغات الاخلية ذات الواجهات الزجاجية بالمبنى.

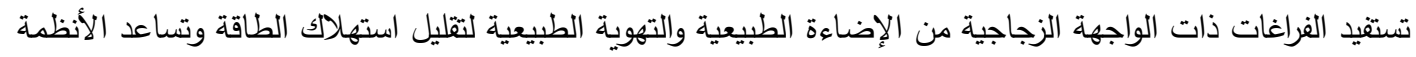
النشطة (أي الإضاءة القابلة للبرمجة) على زيادة فعالية الأنظمة السلبية وتكملها حسب الحاجية الحاجة.
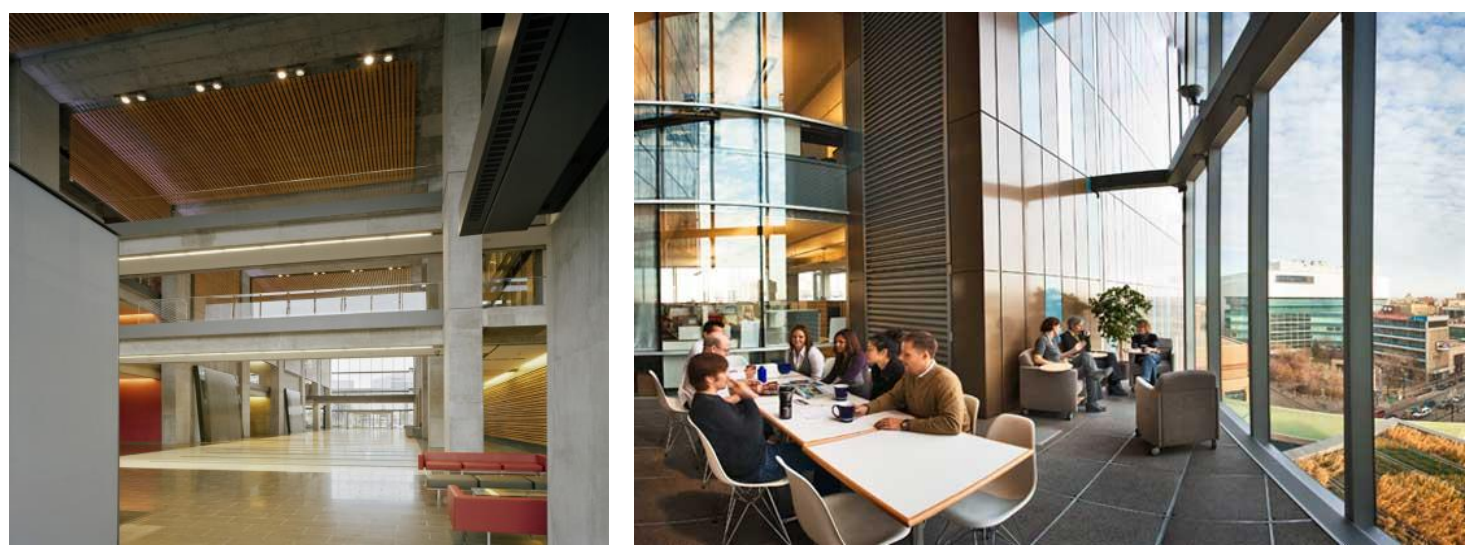

شكل (30) التصميم المستدام ودوره في تحسين جودة وراحة التجربة الإنسانية بالمبنى.

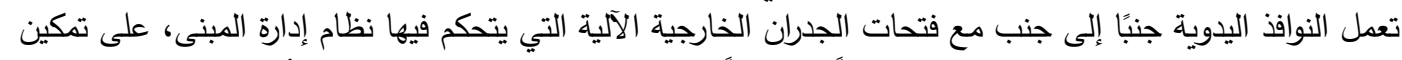

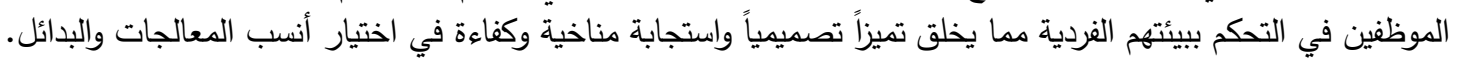




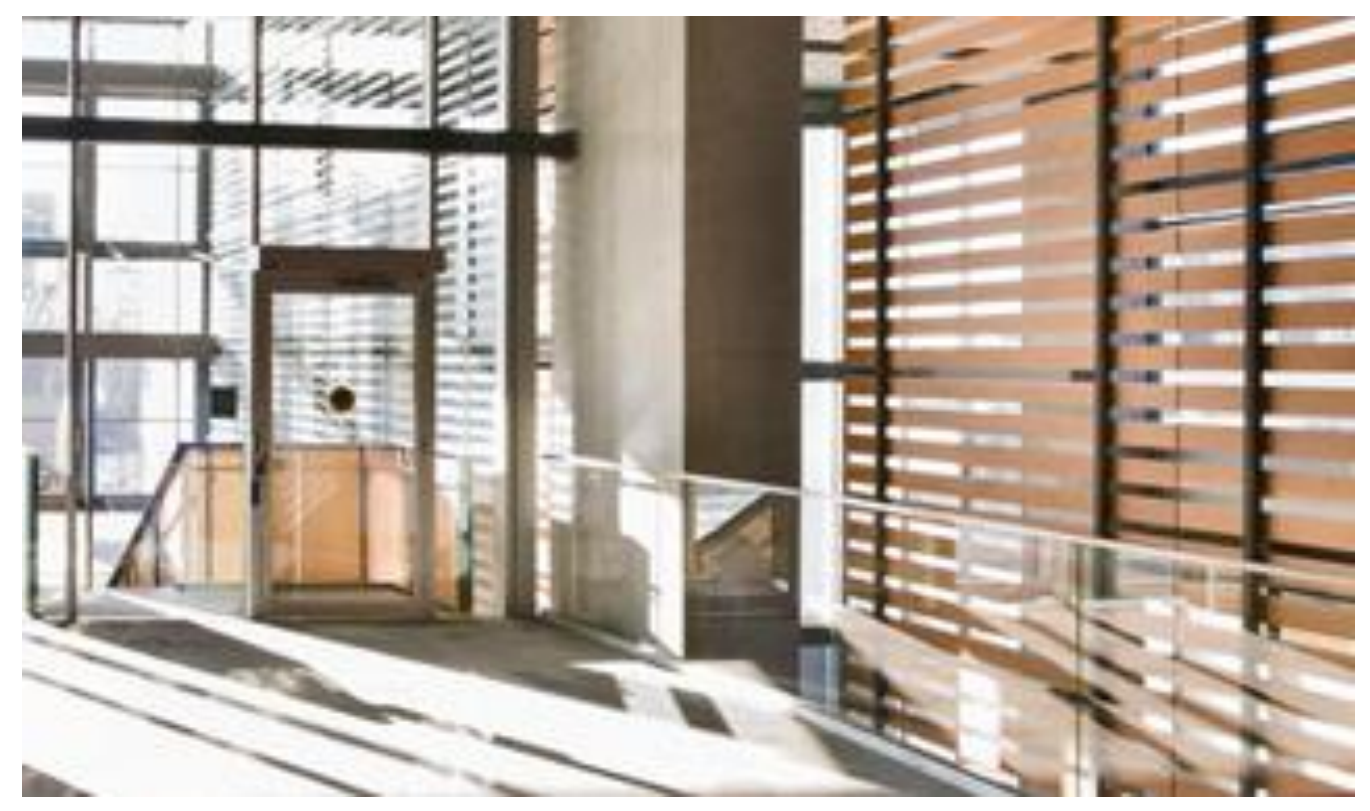

شكل (31) الاستفادة القصوى من ضوء النهار الطبيعي والتهوية

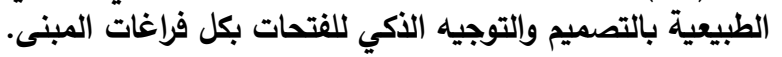

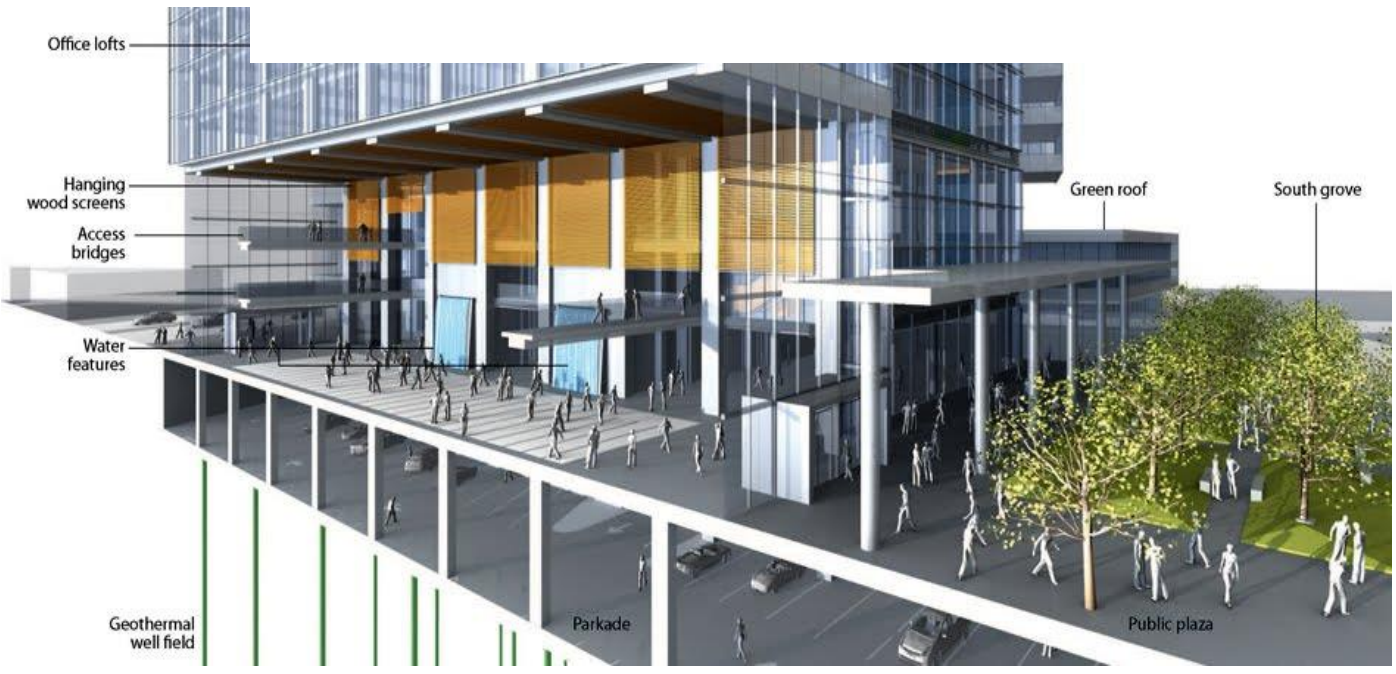

شكل (32) منظر خارجي لمداخل الدور الأرضي ومواقف السيارات.

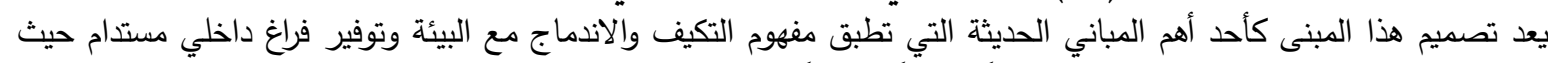
لعبت المواد الأيكولوجية المستخدمة بالمبنى دوراً وظيفياً وجمالياً. ووظفت تقنيات المستقبل في الحيز لتحقيق العمارة الداخلية الدستدامة للكتلة الفراغية.

تحقق بهذا المشروع اتخاذ قرارات صائبة في كل مراحل تتفيذه والتي سيكون لها دور في الحد من الأثار السلبية على البيئة

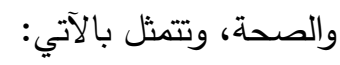

- ترشيد الطاقة وكفاءة استهلاك المياه. - تكامل التصميم. - تقليل أعمال الصيانة والترميم مستقبلاً.
- تحسين إمكانات الموقع والاستفادة منها. - الحد من استخدام مصادر غير متجددة. - استخدام عناصر صديقة للبيئة.

- تحسين نوعية الأنشطة البيئية الداخلية بالمنشأة. 
1. أدى التغير في عناصر البيئة والناتج عن النمو السكاني المتسارع بالمملكة وما يصاحبه من رفاهية واستهلاك وهدر

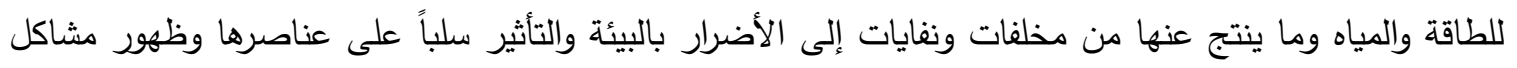
التلوث البيئي الذي يؤثر بدوره على الأنسان والمباني مما يسبب اضطراباً للظروف المعيثية بوجه عام والأخلال بالتوازن الطبيعي. 2. تهدف العمارة الداخلية المستدامة الى دمج التصميم الداخلي مع محتويات البيئة المختلفة والظروف الاقتصادية والنواحي الاجتماعية والتعامل معها كوحدة واحدة. 3. من أهم معايير التصميم الداخلي المستدام بالمملكة العربية السعودية أن يكون التصميم متوافقاً بيئياً وتكنولوجياً وأن يراعي استخدام مواد وموارد متجددة والاهتمام بمصادرها وتوفيرها. 4. يتمثل دور المصمم الداخلي والمعماري الناجح بالمملكة في تقديم تصاميم أكثر حساسية للبيئة السعودية تحقق التوازن بين تفاعل ثلاث منظومات: (المحيط الحيوي، والمحيط الاجتماعي، والمحيط المشيد) ويحافظ على سلامة النظم البيئية وحسن أدائها.

\section{توصيات البحث:}

1. ضرورة الاستفادة من التجارب العالمية التي حققت الاستدامة في تصميم عمارتها الداخلية والاستفادة من خبراتهج بما يناسب بيئتنا السعودية. 2. زيادة الوعي لدى الناس بمدى أهمية تطبيق المنهج البيئي المستدام بالتصميم الداخلي ويكون ذلك بتوجيه الأنظار الى لئي فوائده وإمكانياته في خفض مستوى التلوث البيئي ومراعاة السلامة الصحية للمستفيدين وخفض استهلاك الطاقة والموارد. 3. نتيجة لظهور التقنيات العالية والتكنولوجيا في مجال العمارة والتصميم الداخلي وما ينطوي على اغلبها من نتائج سيئة،

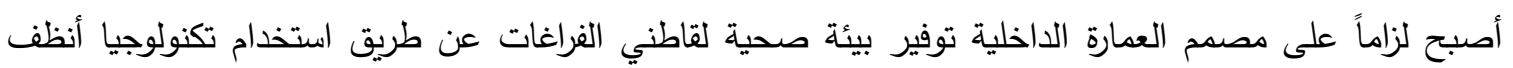
وأكفاء تكون قريبة من قيم انبعاثات الصفر وتقلل من الاستهلاك الكثيف للطاقة. 4. لابد أن يراعى التصميم المستدام بالمملكة العربية السعودية العوامل المناخية من حرارة ورياح وأمطار، مع الاهنية الهتمام بالإضاءة والتهوية الطبيعية وتثجيع استعمال الطاقة المتجددة لأنظمة التدفئة والتبريد وترشيد استعمال المياه. 5. التصميم الجيد للعمارة الداخلية المستدامة بالمملكة يتحقق عبر تكامل مبادئ العمارة التقليدية مع نظم ووسائل التكنولوجيا 
1. Clennan,Jason F. ( 2004) The Philosophy of Sustainable Design. Bainbridge Island: Ecotone Publishing Company.

2. Florez,Laura and Daniel Castro-Lacouture. (2012) "Optimization model for sustainable materials selection using objective and subjective factors" Materials and Design.

3. Giovani, Baruch (1998) Climate Considerations in Buildings \& Urban Design, John Wiley \& Sons, Inc, USA.

4. Kang, M, \& Guerin, D.A (2009) The state of environmentally sustainable interior design practice. American Journal of Environmental Sciences.

5. Mate, K.J. (2006). Champions, Conformists and Challengers: Attitudes of Interior Designers as Expressions of Sustainability through Material Selection. Paper 0066. presented at Design Research Society International Conference. Wonderground. 1-4 November, Lisbon.

6. Nur Ayalp:( 2013) Multidimensional Approach to Sustainable Interior Design Practice, INTERNATIONAL JOURNAL of ENERGY and ENVIRONMENT, Issue 4, Volume 7.

7. Sustainable Design: U.S. General Services Administration, 3 Nov. 2012. Web. 2 Dec. 2012. http://www.gsa.gov/portal/content/10446.

8. Wael Rashdan (2016) The impact of innovative smart design solutions on achieving sustainable interior design, International th11 Conference on Urban Regeneration and Sustainability.

\section{ONLINE SOURCES:}

9. https://new.usgbc.org/leed - U.S. Green Building Council USGBC.

10. https://www.breeam.com - British Council for Sustainable Construction and Green UKGBC.

11. http://www.hpbmagazine.org/Case-Studies/Federal-Center-South-Building-1202-SeattleWA/

12. https://www.zgf.com/project/u.s.general-services-administration-federal-center-southbuilding 1202

13. https://www.gsa.gov/cdnstatic/GSA_FCS_Press_Book_email.pdf

14. http://www.hpbmagazine.org/Case-Studies/Federal-Center-South-Building-1202-SeattleWA/

15. http://www.buildup.eu/fr/node/51248.

16. https://en.wikipedia.org/wiki/Manitoba_Hydro_Place. 